WIDER Working Paper 2020/42

\title{
Riots and social capital in urban India
}

Alia Aghajanian, ${ }^{1}$ Patricia Justino, ${ }^{1,2}$ and Jean-Pierre Tranchant ${ }^{1}$

April 2020 
Abstract: This paper explores the relationship between household exposure to riots and social capital in urban India using a panel dataset collected by the authors in the state of Maharashtra. The analysis applies a random-effect model with lagged covariates to estimate the exogenous effect of riots on social capital. Households living in neighbourhoods prone to riots are more likely to invest in bridging social capital by joining community organizations but reduce face-to-face contact with neighbours. These effects are driven largely by levels of neighbourhood social fragmentation in riot-prone neighbourhoods. There, the salience of social identity is also reduced as individuals attempt to reach out across social divisions. We interpret these results as indicating that households instrumentally use bridging forms of social capital as an insurance against potential future communal violence in socially fragmented contexts where conflicting social groups live alongside each other.

Key words: riots, social capital, trust, bonding social capital, bridging social capital, vignettes, violence

JEL classification: D71, D74, D91, O18

Acknowledgements: The authors would like to thank Jaideep Gupte for his collaboration in the design and implementation of the surveys and Yashodhan Ghorpade for his excellent inputs into the design and implementation of the second wave of data collection. We would also like to thank Mr. Raghu Roy, Mr. Narendra Patel, Mr. Prasad Modak, Ms. Shabana Patel, Mr Yatin Sawant, and others from MaRS Monitoring and Research Systems Private Limited for their great collaboration with the implementation of the two survey waves. The research and data collection in this paper were funded by the Integrated Project MICROCON (2007-12) funded by the European Commission under the 6th Framework Programme (project 28730); the 'Agency and Governance' project funded by a joint grant by the UK Department for International Development (DFID) and the UK Social and Economic Research Council (RES-167-25-0481); the TAMNEAC Training and Mobility Network for the Economic Analysis of Conflict funded by the European Commission 7th Framework Programme (project 263905); and the UK Economic and Social Research Council (ESRC) under the Large Grant project 'Inequality and Governance in Unstable Democracies: The Mediating Role of Trust'.

This study is published within the UNU-WIDER project Inequality and governance in unstable democracies - the mediating role of trust, implemented by a consortium led by Institute of Development Studies (IDS). The support of the UK Economic and Social Research Council (ESRC) is gratefully acknowledged

\footnotetext{
${ }^{1}$ Institute of Development Studies, University of Sussex, Brighton, United Kingdom. ${ }^{2}$ UNU-WIDER, Helsinki, Finland. Corresponding author: alia.aghajanian@gmail.com
}

This study is published within the UNU-WIDER project Inequality and governance in unstable democracies—-the mediating role of trust, implemented by a consortium led by Institute of Development Studies (IDS).

Copyright (C) UNU-WIDER 2020

Information and requests: publications@wider.unu.edu

ISSN 1798-7237 ISBN 978-92-9256-799-6

https://doi.org/10.35188/UNU-WIDER/2020/799-6

Typescript prepared by Siméon Rapin.

United Nations University World Institute for Development Economics Research provides economic analysis and policy advice with the aim of promoting sustainable and equitable development. The Institute began operations in 1985 in Helsinki, Finland, as the first research and training centre of the United Nations University. Today it is a unique blend of think tank, research institute, and UN agency - providing a range of services from policy advice to governments as well as freely available original research.

The Institute is funded through income from an endowment fund with additional contributions to its work programme from Finland, Sweden, and the United Kingdom as well as earmarked contributions for specific projects from a variety of donors.

Katajanokanlaituri 6 B, 00160 Helsinki, Finland

The views expressed in this paper are those of the author(s), and do not necessarily reflect the views of the Institute or the United Nations University, nor the programme/project donors. 
Riots and violent protests have been on the rise in the last two decades, causing deaths, injuries, and serious economic damage in many parts of the world. Just between 2017 and 2018, the number of riots worldwide increased by almost 25 per cent (Kishi and Pavlik 2019). These levels of civil upheaval are likely to have profound effects on societies, economies, and political processes. However, even though riots have preoccupied scholars for several decades, this literature has largely focused on understanding the causes of riots (Brass 1997; Wilkinson 2004; DiPasquale and Glaeser 1998; Horowitz 2001; Petersen 2002). Although a few studies have examined the economic costs of riots (Collins and Margo 2007), analyses of the social consequences of riots and the mechanisms that might shape them remain scarce.

These consequences are likely to be particularly pronounced in densely populated (often informal) urban settlements made up of diverse social groups where a melting pot of civilizations live alongside each other in extremely stressful situations. Riots are by and large an urban phenomenon (DiPasquale and Glaeser 1998; Horowitz 2001; Wilkinson 2004), ${ }^{1}$ and recent high rates of urbanization have resulted in increased proximity between different social groups. According to the United Nations, over one billion people across the world live in such conditions. ${ }^{2}$ This number is estimated to double by 2030 (UNHabitat 2003). The effects of civil violence on these communities and neighbourhoods is likely to be considerable.

This paper studies the effects of exposure to riots that occur in urban neighbourhoods on household social capital, and what mechanisms may explain this relationship. The paper focuses on the Indian state of Maharashtra, and is based on a unique longitudinal household-level survey collected by the authors in riot and non-riot affected neighbourhoods located in urban (largely informal) areas across Maharashtra. To the best of our knowledge, this is one of the first studies on the relationship between civil unrest and social capital in informal urban settlements.

The social capital effects of urban riots are a priori unclear. Since Horowitz $(2000,2001)$, there has been an implicit assumption in the literature that civil violence has adverse effects on social relations. Riots that emerge between ethnic, religious, or other cultural groups tend to foment further resentment between groups and reinforce in-group biases (Petersen 2002). However, research in civil war contexts has revealed a positive relationship between individual exposure to violence and forms of civic engagement and social cooperation, including participation in community organizations (Bellows and Miguel 2009), voting (Blattman 2009), and pro-social behaviour (Gilligan et al. 2014; Voors et al. 2012). More recent research has qualified that these positive effects may be limited to those among the same social groups (Bauer et al. 2014, 2016). These studies have focused on postwar contexts, and there has been to date limited systematic understanding of how different dimensions of social capital may change in socially and politically unstable areas outside these extremely violent contexts.

Empirically, identifying the effect of riots on social outcomes is a challenging task because standard regression estimates may be affected by reverse causality and omitted variable biases. In the case of India, there is reason to believe that social capital at the neighbourhood level may shape the likelihood of riots emerging in specific areas (Varshney 2002). At the same time, economic shocks, such as price rises, urban planning processes, such as the demolition of slum areas, and political processes, such as elections, may affect the onset and intensity of riots and levels of social capital simultaneously in given neighbourhoods. In order to address these endogeneity concerns, this study makes use of a random-

\footnotetext{
1 Though some riots may expand into rural areas, as illustrated in examples analyzed in Horowitz (2001).

2 UN Statistics Division. Available at: https://unstats.un.org/sdgs/report/2019/goal-11/ (accessed 11 March 2020)
} 
effect model with lagged covariates (exploiting the longitudinal nature of the data). We measure social capital in terms of bridging and bonding social capital (Putnam et al. 1994). Measures of bridging social capital include household participation in civic organizations. Bonding social capital is illustrated by levels of trust in neighbours and participation in face-to-face discussions with neighbours.

As a novel contribution, we also investigate the mediating factors that may shape the relationship between riot exposure and household social capital. Given the ethnic dimension of most riots in India, we hypothesize that the effect of riot exposure on social capital is shaped by levels of social diversity and the salience of individual identities in each given neighbourhood. Social diversity is measured using indices of social fractionalization and polarization of religious and caste groups. The salience of identity is measured through vignettes included in the survey. This methodology allows us to elicit true behavioural responses by asking respondents to react to several scenarios designed to measure trust and cooperation where we randomly change the social identity of the characters in order to emulate exchanges between different religious and caste groups.

The main results show that households in neighbourhoods exposed to riots in 2010 are more likely to join neighbourhood organizations in 2012, but less likely to participate in face-to-face discussions. There is no direct effect of riot exposure on how households trust their neighbours. We interpret these results as indicating that exposure to riots leads to households favoring forms of bridging social capital, possibly as an insurance against future riots and their adverse effects. This effect is driven by highly fragmented, riot-prone neighbourhoods, where households build networks with other social groups by joining local community organizations. Bonding social capital is reduced in riot-prone and fractionalized neighbourhoods, most likely due to suspicion and reduced lack of trust in neighbours. We find, in addition, evidence for a fading in the salience of social identities - which is usually very strong in all aspects of life in India - in neighbourhoods prone to riots. Taken together, these findings suggest that in contexts of informal and violence-prone urban settlements, where different social groups are forced to live in close physical proximity, households tend to invest in between-group interactions and behave in ways that bridge across social divisions, even when experiencing reduced levels of trust and confidence in neighbours. This interpretation reflects an instrumental use of social capital in co-ethnic communities where the threat of violence is high.

This paper is related to at least three bodies of literature. The first is the literature on ethnic riots (Horowitz 2001), including a large literature on India (Wilkinson 2004), which to date has offered only limited understanding of the consequences of riots. We show that riots have a substantial impact on social capital. We show also that social fragmentation plays an important role in explaining this relationship, whilst individual identity loses salience in riot-prone neighbourhoods, despite the importance of caste and religious divisions in India. The second is a smaller body of research on the effect of violence on social capital in contexts of civil war (reviewed in Bauer et al. (2016)). The paper extends this literature to analyze the role of low-intensity violence (in the form of riots). A similar analysis is done in Hager et al. (2019), who focus on one riot that took place between two ethnic groups in the city of Osh in Kyrgyzstan. Our paper examines exposure of households to riots across time using a representative survey of informal settlements in a country (India) where riots are endemic to social, economic, and political life. Finally, we contribute to the literature on the provision of public goods in ethnically diverse societies. Several studies have shown that collective action that sustains the provision of public goods is more challenging in heterogeneous societies (Alesina et al. 1999; Alesina and La Ferrara 2000, 2005; Habyarimana et al. 2007; Miguel and Gugerty 2005; Vigdor 2004). We show that the threat of violence in heterogeneous communities may facilitate some forms of collective action, as these can be used as ways of bridging across social divides and as insurance against the adverse impact of civil violence. 
The literature on the effects of violence on social behaviour has relied largely on evolution models of social cooperation where the threat of violence favors within-group cooperation at the expense of between-group cooperation, which may in turn lead to hostility towards others outside the immediate social group (Bowles and Gintis 2011). Recent research from civil war contexts has revealed a positive relationship between exposure to armed violence and forms of civic engagement and cooperation (Bauer et al. 2014; Bellows and Miguel 2009; Blattman 2009; Gilligan et al. 2014; Voors et al. 2012), particularly among those from the same community (Bauer et al. 2014, 2016). Thus, based on the civil war literature, we would expect riots to increase 'bonding' social capital (which would strengthen withingroup cooperation by encouraging social norms that keep the group together), while reducing 'bridging' social capital across opposing groups.

These predictions may not hold in contexts outside civil wars. Extreme poverty and lack of economic opportunity have forced Indians-and many other people in other developing countries-across different religious, caste, and cultural groups out of rural areas and into the cities, in search of a more prosperous life. What they find is often unplanned infrastructure, lack of basic living conditions, and close proximity between new migrants who must live side-by-side under extremely challenging circumstances (Mazumdar 1987; Deaton and Dreze 2002). In these contexts barriers to choosing where to live are very high, even between groups that traditionally oppose each other. It is not therefore a surprise that violence is endemic in slum areas in India and elsewhere.

Under these complex social arrangements, the effects of urban violence on social capital are theoretically ambiguous. The literature on civil wars explains a positive effect between war victimization and social capital based on theories of post-traumatic growth (Tedeschi and Calhoun 2004), whereby victimized people find strength in adversity and come together to overcome previous trauma. This mechanism may arise also in riot-prone areas when, under the threat of violence, close social proximity between different ethnic, religious, or cultural groups may lead to tolerance rather than hostility (Côté et al. 2015). For instance, in India, historical trade exchanges between Hindu and Muslims living in the same communities have reduced the likelihood of ethnic animosity (Jha 2013). According to the widely studied social contact theory, proximity between social groups, like that observed in urban slums, and shared experiences (like for instance riots) may promote tolerance and reduce social distances (Allport 1954) - see also review of latest evidence in Paluck et al. (2019). Both post-traumatic growth and social contact theories predict an increase in social capital as a result of riot exposure.

However, competition between social groups implies that forced direct proximity between heterogeneous social groups, due to increased urbanization or migration flows, may trigger ethnic animosities and possibly conflict (Forbes 1997; Caselli and Coleman 2013). Ethnic violence will, in turn, destroy further the social fabric of affected communities, particularly in those communities where rival groups (for instance, Muslims and Hindus in the case of India) live in close proximity (Horowitz 2001). Thus, social competition theories predict a reduction in social capital among riot-exposed communities. Nevertheless, relations between rival groups in contexts of violence may depend on the nature of this violence, particularly on whether this is indiscriminate (targeting everyone in a community randomly) or selective (targeting specific individuals and households due to idiosyncratic characteristics) (Kalyvas 2006). Although riots may affect some people indiscriminately, there is strong evidence of selective targeting in urban riots in general (Horowitz 2001). Selective violence has also been found in Maharashtra where specific slum dwellers are targeted by rioters (Gupte et al. 2014). Therefore, households living in close proximity to those that may become their assailants when a religion or caste-based riot breaks out may want to minimize their exposure to being a target of violence. Like with other forms of coping strategies under adverse economic conditions (Fafchamps and Gubert 2007), social relations and forms of social cooperation that bridge across social divides may become a valuable investment for households living 
under unstable sociopolitical conditions. This instrumental use of social capital has been documented in other areas, such as accessing jobs and social networks (Portes 1998). Co-ethnic civic associations, in particular, may be useful sources of information (Caria and Fafchamps 2019), including about factors that may trigger the next riot, like for instance rumors and warnings that tend to circulate during riot preparations (Horowitz 2001). Access to such information is crucial in ensuring that households protect lives and property before a riot erupts. Under these circumstances of social/ethnic competition and uncertainty (due to the threat of violence), exposure to riots may reverse the previous result and lead to higher levels of social capital - at the very least of social capital that can be used instrumentally to avoid exposure to future riots.

In summary, existing theoretical frameworks predict that riot exposure may reduce social capital if it breaks the social fabric of local neighbourhoods by increasing in-group biases and out-group prejudices, or it may increase social capital if it promotes empathy and tolerance across social groups and among individuals of different cultural and social backgrounds or if investments in social capital are seen as a useful instrument of social insurance against riot threats. Which of these theoretical approaches may prevail will depend on the balance achieved in the social composition and social preferences that characterize each community. Traditionally, the literature has focused on two important dimensions of social composition: levels of community social diversity and how attitudes towards others are shaped by social identities.

\subsection{Social diversity}

It is generally postulated that homogeneous groups achieve higher levels of social capital because the costs of coordination and cooperation are lower among these groups (Alesina and La Ferrara 2000). The levels of social heterogeneity that characterize densely populated urban settlements have generally been found to reduce group cooperation and the effectiveness of public good provision (Alesina and La Ferrara 2005; Bardhan 2005; Miguel and Gugerty 2005). Group heterogeneity has also been found to reduce participation in community groups, although this matters less for groups that require low levels of daily direct contact (Alesina and La Ferrara 2000). Large levels of social diversity in riot-prone contexts may in addition reduce social capital when violence pits neighbour against neighbour. Kalyvas (2006) discusses how suspicion, mistrust, and fear hinders social relations between community members in contexts of civil war. Nunn and Wantchekon (2011) describe how individuals tried to protect themselves against the slave trade by denouncing others in their communities, leading to long-lasting forms of mistrust. Horowitz (2001, p. 11) documents how ethnic riots spread 'bitterness and suspicion and aloofness'. In the case of India, Hindu-Muslim riots are pervasive and more often than not result in deepening the social distances between the two religious groups (Varshney 2002; Wilkinson 2004).

However, under stressful conditions, households in heterogeneous communities may want to find ways of coping and insuring themselves against future shocks—-such as riot exposure. This is particularly true when households are not able to sort themselves easily into homogeneous groups. Although segregation is common in large urban areas, physical proximity and lack of infrastructure may force people into social proximity, particularly in unplanned slum areas. Even though people from the same religion or caste may form small homogeneous clusters, living in slums will still imply close proximity to other social groups, unless the household is able to move out of the slum altogether (Jaffrelot 2007; Spater 2019).

We hypothesize that this instrumental dimension of social capital is central to socially diverse informal urban settlements where rival social groups must live side-by-side under stressful situations. Under the close threat of ethnic violence, inter-group cooperation in heterogeneous communities becomes a survival strategy. The empirical analysis in Section 6.1 will test this hypothesis by determining empirically the net effect of potentially negative or positive impacts of social diversity on social capital in riot-prone neighbourhoods in Maharashtra. 


\subsection{Social identity}

In addition to group factors, individual social preferences and prejudices may also shape the relationship between riot exposure and social capital. Based on seminal studies by Tajfel et al. (1971) and Tajfel (1978), a large literature has shown that shared identities shape individual decisions in several areas of life, including who to marry, who to exchange goods with, and how to vote (Akerlof and Kranton 2000; Hoff and Pandey 2006; Chen and Li 2009; Afridi et al. n.d.). In India, religious and caste identities are central to all aspects of life (Iyer 2016). There is also substantial evidence that social capital investments are shaped by shared identities when individuals show prejudice against and aversion to mixing with others from different backgrounds (Alesina and La Ferrara 2000). In riot-prone contexts, shared identities may reduce social interactions between groups when they reinforce in-group biases. For instance, Beber et al. (2014) show that Northern Sudanese individuals exposed to an ethnic riot in Khartoum were more likely to support independence of South Sudan because they were unwilling to continue living alongside Southern Sudanese co-citizens. In Israel (Canetti-Nisim et al. 2008) and in the USA (Huddy et al. 2005; Davis and Silver 2004), the threat of terrorism has resulted in negative stereotyping of Muslim groups. In all these cases, exposure to violence or the threat of violence increased in-group bias through increased prejudice towards those of different social identity.

On the other hand, it is possible that in politically unstable areas individuals may exhibit larger level of empathy towards other groups. Corno et al. (2019) show evidence for this mechanism in the case of an inter-racial policy in South Africa that promoted room sharing across black and white university students in order to break stereotypes in post-apartheid South Africa. Individuals may want also to reach out across identity divides to prevent further violence, as studies have shown in the case of Israelis living close to areas targeted by Palestinian attacks who support the two-state solution (Gould and Klor 2010) and Chechen rebels under the threat of Russian forces that refrain from retaliation (Lyall 2009). In these cases, shared identities become less salient in social and economic exchanges and political attitudes because the threat of being targeted by ethnic violence is high. We hypothesize that in the case of slums in India, where rival groups live in close proximity, the salience of shared identities may be reduced in ways that will allow individuals to reach across social divides. We test this hypothesis empirically in Section 6.2. First, we turn to the discussion of the data and the estimation of the direct effect of riot exposure on social capital.

\section{Data and variables: the Maharashtra household longitudinal survey on civil violence and welfare (MHLS)}

India has historically registered some of the highest numbers of riots and riot-related fatalities in the world (Kishi and Pavlik 2019), which have been particularly endemic to informal urban settlements (Varshney 2001; Wilkinson 2005, 2004; Brass 1997). Almost 110 million people live in slum areas in India and 11 million in Maharashtra (the highest in India). Riots have been a constant feature of life in urban Maharashtra in the last decades, with particular deadly years in 1970, 1984, and 1992-93, when major Hindu-Muslim riots broke out across the state (Varshney 2002; Wilkinson 2004), often fueled by competing political interests (Wilkinson 2004) and often involving extremist groups, such as the Shiv Sena, a Hindu nationalist political organization, which has been operating in Maharashtra since the 1960s (Horowitz 2001). In addition to these particularly violent years, riots break out nearly every year in Maharashtra (Figure A1 in the appendix). ${ }^{3}$

\footnotetext{
3 This data was collected by the authors with the support of a Marathi speaking research assistant, who read through the Maharashtra edition of the Times of India and the leading Marathi news site, the Loksatta. Details are provided in Gupte et al. (2014). In total, we coded 225 riots that took place from the 1st of January 2008 to the 1st of January 2012.
} 
The empirical analysis in this paper is based on a panel dataset collected by the authors among 1,089 households interviewed in 2010 and 2012 in 45 urban neighbourhoods in Maharashtra. This dataset was collected using a clustered sample approach that took into consideration the fact that riots are concentrated in certain areas across Maharashtra and are rare events, even if regular and persistent in many parts of the state (Gupte et al. 2014). We started by using district-level data from the Maharashtra police between 2003 and 2008 to identify three district categories: high rioting ( 5 or more riots per year), medium rioting (between 1.5 and 5 riots per year) and low rioting (less than 1.5 riots per year). We then selected within these categories districts that offered a good spread of administrative and sociocultural divisions in the state, resulting in three districts in the medium and low rioting categories and four high rioting districts. This process is described in detail in Gupte et al. (2014).

In each of the ten districts, we collected information on riot events in the 24 months prior to the collection of the first panel wave (2008-10) using newspaper information (Table A1 in the appendix). The aim of this work was to identify as precisely as possible urban areas where riots took place (our sites of interest). We then matched these sites to a list of voting-booths obtained from the Maharashtra Election Commission and randomly selected 45 neighbourhoods. Coincidentally, though not surprisingly, these were all located in slum areas.

In the last stage of the sampling process, we randomly selected households to be interviewed in the 45 neighbourhoods. Given the lack of accurate census information in slum areas, we selected households following a random walk strategy whereby each field team started walking from equidistant points in the perimeter of each neighbourhoods towards the center, turning right at each junction and making sure that no alley was missed. This was an important aspect of the strategy to minimize missing the most vulnerable households. Households were randomly selected along the walk using a skip pattern (every $7^{\text {th }}$ or $8^{\text {th }}$ household in larger neighbourhoods and every $4^{\text {th }}$ or $5^{\text {th }}$ in smaller neighbourhoods). This was a time-consuming process due to the haphazard nature of dwellings in these contexts but resulted in one of the few available representative longitudinal surveys of slum populations in the world.

We went back to retrace these households in 2012. To do this, we used cell phone numbers we had collected in 2010 as well as detailed maps of each neighbourhood (including all dwellings and landmarks) hand drawn by a cartographer who was part of the enumeration team. Despite our best efforts and detailed planning, we were not able to find all households from the original sample. In total, 874 out of the original 1,089 households were traced or 80.4 per cent of the original sample. ${ }^{4}$

The MHLS questionnaire includes several questions on the exposure of households to riots (detailed in Gupte et al. (2014)) as well as a detailed module on social capital. We discuss below how we use the MHLS to measure our main variables of interest.

\subsection{Riot exposure}

In India, a riot is officially defined as an assembly of more than five people who use violent means to achieve a common goal (Wilkinson 2009), and fall within the categories defined in Horowitz (2001, p. 1) of 'an intense, sudden, though not necessarily wholly unplanned, lethal attack by civilian members of one ethnic group on civilian members of another ethnic group'. The majority of riots in India are between Hindu and Muslim groups, although there have also been instances of riots between caste and migrant groups (Wilkinson 2004). While the definition of a riot in India is broad, riots are severely under-reported because policemen and politicians prefer to convey a peaceful and well-functioning society (Wilkinson

\footnotetext{
4 We noted in detail the reasons why each household could not be tracked. Eighty-one households were not found because they had since migrated. We were not able to find the original dwellings of 68 households because a particular slum in Mumbai was destroyed by a fire. In 65 households, no respondent was available after repeated visits. In 5 cases, the respondents refused to be re-interviewed. We discuss later in the paper that attrition did not introduce selection bias into our main results.
} 
2009). Although we were able to collect subdistrict-level riot event data to construct the main sample, this information was not available at the neighbourhood level. In the absence of such data, we measured household exposure to riots using a question that asks the respondent: 'In the last 12 months, have any of the following events occurred in your neighbourhood?'. The events include riots as well as modalities of violence commonly associated with riots such as stone pelting, public fights, bottle throwing, and tire burning. Twenty-three per cent of respondents reported a riot taking place in their neighbourhood in 2010 (Table A1 in the appendix). Self-reported data entails some challenges since such data can be under- or over-reported by households and could be correlated with household characteristics, including social capital. We address potential self-reporting biases in three ways. First, we control for household income as this variable may be correlated with the likelihood of a household being directly affected by the riot; for instance, through targeting by looters or because they live in makeshift houses that are easier to destroy. (DiPasquale and Glaeser 1998; Gupte et al. 2014). Second, our main empirical analysis relies on households being asked about a riot taking place in the neighbourhood rather than the household experiencing the riot directly. This alleviates concerns about under-reporting among households that may be scared to admit their involvements in riots and about over-reporting among households that might be expecting compensation in return for their exposure to riots. Finally, we also accounted for the possibility that households may have conflicting views about the occurrence of a riot and where. This potential measurement error could occur because the household is genuinely confused or because some riots might have only affected parts of the neighbourhood and thus specific households may have been unaware of the riot. In order to minimize this potential bias, we computed for each neighbourhood the proportion of households who reported a riot. By aggregating this variable, we are able to address some of these discrepancies and get a fuller picture that accounts for all responses. We then partitioned the sample into riot-affected and less affected sites based on whether at least 30 per cent of respondents in a given site report a riot in their neighbourhood. ${ }^{5}$ While this might miss out on some information, it means this paper provides a conservative measure of riot exposure, rather than risks over-estimating the results. ${ }^{6}$ Figure 1 plots the proportion for each neighbourhood.

Figure 1: Proportion of self-reported riots in each neighbourhood

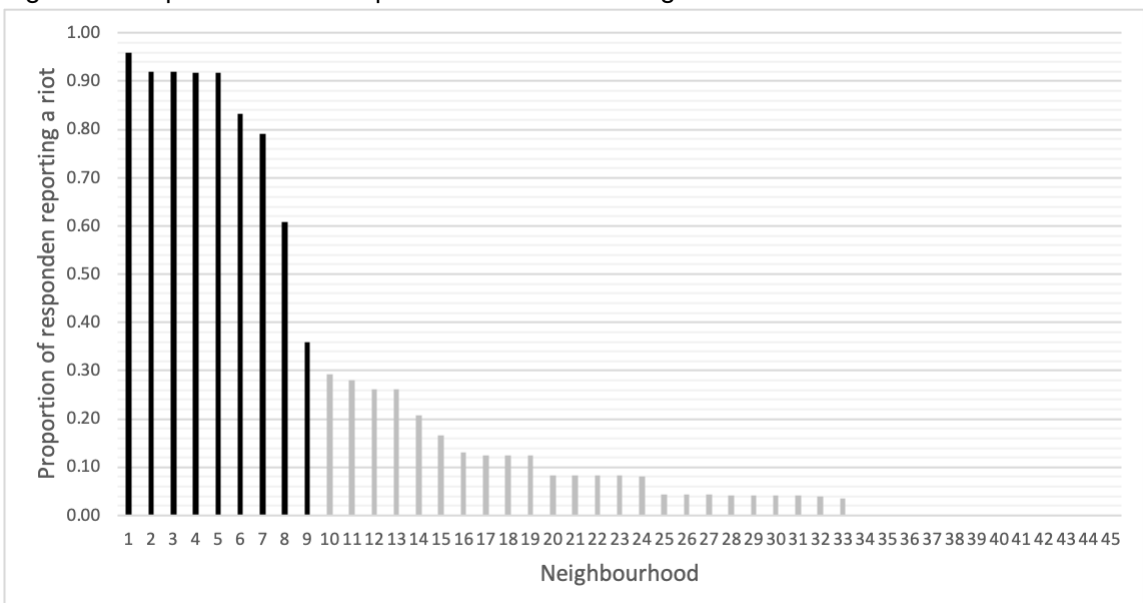

Notes: bars with solid shading are neighbourhoods where the proportion is higher than 30 per cent.

Source: MHLS 2010.

5 This number was chosen as a cut-off point because this was the average number of households reporting a riot in neighbourhoods where at least one household reported a riot. When including neighbourhoods where no households reported a riot, the average is 23 per cent (Table A2 in the appendix).

6 As a robustness check we repeated the analysis using different cut-offs for the proportion of households reporting a riot. Within the range of 20 to 80 per cent of households reporting a riot, the impact effect of rioting on social capital is largely similar to the results we report in the next section (Figure A2 in the appendix). 


\subsection{Social capital}

The definition of social capital often encompasses many indistinct concepts (Portes 1998). Despite this ambiguity, there seems to be a growing consensus that 'social capital stands for the ability of actors to secure benefits by virtue of membership in social networks or other social structures' (Portes 1998, p. 6). Other concepts that have been added to the mix include social cooperation and norms of trust and reciprocity (Putnam et al. 1994). Given the variation in definitions, it makes sense to understand social capital as a multi-faceted concept and explore each dimension independently (Dasgupta and Serageldin 2002; Grootaert and van Bastelaer 2002). We use three variables that represent different dimensions of social capital. The first is household participation in community organizations or groups, which measures bridging forms of civic association (Putnam 2000; Varshney 2002). In our survey, 15.9 per cent of respondents reported that they or a member of their household belong to a neighbourhood group or organization. These include women's groups, political parties, gyms, ${ }^{7}$ religious organizations, local mohalla committees, caste organizations, trade unions, student organizations, cooperatives, sports or cultural groups, youth organizations, farmer organizations, village organizations, and others. Women's groups are the most common form of neighbourhood organization (10.3 per cent), which reflects the known importance of women's groups in slum areas in India, ${ }^{8}$ and historically as part of the organization of peace committees in riot-prone situations (Katzenstein 1989). Other relevant organizations include political parties (2.2 per cent of total respondents), gyms (1.9 per cent), and religious organizations (1.5 per cent). The second measure is self-reported trust towards neighbours, which asks whether the respondent would trust their neighbours to safe keep their money, a measure of pro-social preferences commonly used in the literature (Voors et al. 2012). Just over 17 per cent of respondents reported that they would be willing to trust their money or assets for safekeeping with their neighbours. The final measure is household participation in discussions, which captures face-to-face interactions between neighbourhood members, and an important feature of communal life in India (Varshney 2002). Fortytwo per cent of households report participating in face-to-face discussions. All these are binary variables with value ' 1 ' when the respondent (most frequently the household head) reported that they belonged to a neighbourhood organization, trusted their neighbours with their money or assets, or participated in neighbourhood discussions. Table A3 in the appendix shows how each of these variables was measured in the survey questionnaire, while summary statistics are provided in Table A4. Table 1 disaggregates household measures of social capital across riot-prone and peaceful neighbourhoods. Respondents who have at least one household member belonging to an organization are more likely to live in riot-prone neighbourhoods. This difference is statistically significant. The other social capital variables move in the opposite direction: trust towards neighbours and participating in face-to-face discussions are significantly lower in riot affected neighbourhoods.

\footnotetext{
7 This was included because gyms in many slum areas in Maharashtra are well-known recruitment grounds for the Shiv Sena.

8 For several examples, see: https://www.globalgiving.org/projects/self-reliance-and-resilience-in-slum-womens-groups/ reports/
} 
Table 1: Differences in social capital variables separated by whether at least $30 \%$ of neighbourhood reports a riot

\begin{tabular}{lcccc}
\hline \multicolumn{1}{c}{ Variable } & \multicolumn{4}{c}{ Mean } \\
\hline & Riot & No riot & Diff. \\
\hline Household member belongs to an organization & 0.27 & 0.14 & $0.12^{* * *}$ \\
& $(0.03)$ & $(0.01)$ & $(0.03)$ \\
Trust towards neighbours & 0.11 & 0.19 & $-0.07^{* *}$ \\
& $(0.02)$ & $(0.02)$ & $(0.03)$ \\
Household participates in community discussions & 0.34 & 0.45 & $-0.1^{* * *}$ \\
& & $(0.04)$ & $(0.02)$ & $(0.02)$ \\
\hline
\end{tabular}

Notes: standard errors in parentheses. $* p<0.1, * * p<0.05, * * * p<0.01$.

Source: MHLS 2012.

\subsection{Control variables}

We employ a range of respondent, household, and neighbourhood-level controls summarized in Table A2 in the appendix and found to be important predictors of social capital (Glaeser et al. 2002; Alesina and La Ferrara 2002). These include the gender of the respondent as some studies have found that women are less likely to trust others because they feel discriminated against (Alesina and La Ferrara 2002); age (Glaeser et al. 2002); and house ownership, since home owners may have higher levels of social capital because of their long-term commitment to their community (DiPasquale and Glaeser 1999; Glaeser et al. 2002). Some studies have found income to be an important predictor of social capital (DiPasquale and Glaeser 1999). However, other studies have also shown how high social capital leads to higher levels of income (Narayan and Pritchett 1999; Knack and Keefer 1997), suggesting a potentially endogenous relationship between these two variables. We account for this by using lagged income levels and a random effects model, as we discuss below. We control, in addition, for various identity indicators that characterize the social composition of the community (Alesina and La Ferrara 2000). Variables include whether the household is Muslim, whether their mother tongue is Marathi, and whether the household belongs to the largest caste or religious group in the neighbourhood. We also expect household size to play a significant role, because larger households may have more opportunity to engage in social capital. Finally, we collected neighbourhood-level indicators from the field site maps which illustrate the level of formal and informal institutions. These include the presence of a police station, a chowk, ${ }^{9}$ a Hindu temple, a mosque, and a market.

\section{$4 \quad$ Empirical strategy}

As discussed in Section 2, the social composition of neighbourhoods provides important contextual explanations for why riots emerge and their consequences. Neighbourhood-level variables, such as local institutions and cultural characteristics, are thus likely to be important determinants of urban riots in Maharashtra. However, these variables are also key determinants of social capital (Putnam 2000). Therefore, including these variables as controls in a standard OLS estimation would introduce serious biases in the results. In order to alleviate this potential endogeneity bias, we estimate a random-effect model, which controls for neighbourhood-level unobserved heterogeneity. ${ }^{10}$ Considering that the main variables of interest are at the neighbourhood level, this will eliminate the interdependence of residuals between households caused by omitted variable bias. However, the random-effect models rely on a very

\footnotetext{
9 A chowk is the area at an intersection of two roads, which usually serves as a small open market.

10 In addition, we control for a range of neighbourhood-level variables as described earlier. Household-level characteristics may also be confounding factors, and we include several household-level controls to correct for this, as discussed above.
} 
strong assumption: that the random intercepts must be independent of the covariates. If this assumption does not hold, the estimation will yield biased results. This has made random-effect models unpopular, and most studies on the consequences of violent conflict rely on fixed-effect models instead. However, fixed effects would limit our analysis since we are interested in identifying specific neighbourhood effects that would be wiped out in a fixed effects specification.

The assumption that the random intercepts must be independent of the covariates could fail if we suspect an interdependence between neighbourhood institutions (the random intercept) and one or more of the covariates. Mundlak (1978) and Chamberlain (1984) have developed a useful tool to solve this problem by controlling for within-neighbourhood means of the covariates. In order to do so, we estimate the following equation:

$$
P\left[S_{i, n}=1\right]=\Phi\left[\beta_{1} X_{i}+\beta_{2} R_{n}+\beta_{3} Z_{n}+\delta_{n}+{ }_{i}\right]
$$

where $P\left[S_{i, n}=1\right]$ if household $i$ in neighbourhood $n$ displays a given social capital, and $P\left[S_{i, n}=0\right]$ otherwise. $\Phi$ is the probit function, or an inverse standard normal transformation of covariates. $X_{i}$ denotes household-level variables, $R_{n}$ refers to neighbourhood rioting, and $Z_{n}$ includes a set of neighbourhood characteristics. $\delta_{n}$ are the neighbourhood-level random effects. The Mundlak-Chamberlain decomposes $\delta_{n}$ into a function of the within-neighbourhood means of the covariates $X_{i}$ and random neighbourhoodlevel intercepts, as shown in equation 2.

$$
\delta_{n}=\mu_{n}+\theta \bar{X}_{n}
$$

Any dependence between the covariates and the neighbourhood intercepts is captured by the set of within-neighbourhood means of the covariates $X_{i}$. By controlling for the neighbourhood-level means of $X_{i}$, the intercept $\mu_{n}$ is considered to be independent of $X_{i}$. This ensures that the assumption required for a random-effects estimation is satisfied.

The second potential source of endogeneity bias results from the fact that social capital may be both a determinant and a consequence of violence. Neighbourhoods with dense ties and high social capital could be targeted by rioters for political or economic reasons. Or, as discussed in Varshney (2001), neighbourhoods with high levels of civic association may be less likely to be affected by riots. This potential reverse causality can yield a biased estimate of the effect of riots on social capital. In order to deal with this potential bias, we make use of the longitudinal nature of the data and include in the regression the lag of all covariates by one time period. This ensures that the riots in $2010(t-1)$ occur before the social capital observed in $2012(t)$, which eliminates concerns for possible reverse causality.

The combination of lagged covariates, random effects, and neighbourhood-level effects gives us reasonable confidence that our estimates are the result of an exogenous relationship between riot exposure and social capital. By applying these strategies, we estimate the following equation:

$$
P\left[S_{i, n, t}=1\right]=\Phi\left[\beta_{1} X_{i,(t-1)}+\beta_{2} R_{n,(t-1)}+\beta_{5} Z_{n,(t-1)}+\theta \bar{X}_{n,(t-1)}+\mu_{n}+{ }_{i}\right]
$$

where $P\left[S_{i, n, t}=1\right]$ if household $i$ in neighbourhood $n$ at time $t$ displays a given social capital, and $P\left[S_{i, n, t}=0\right]$ otherwise. The vector of regressors $X_{i(t-1)}$ includes the lags of various household characteristics that are likely to be correlated with riots and social capital, such as household size or income. As per the Mundlak-Chamberlain approach, $\bar{X}_{n,(t-1)}$ is a set of neighbourhood averages of the household and respondent covariates. The variable $R_{n,(t-1)}$ takes the value 1 if the neighbourhood was affected by a severe riot (if at least 30 per cent of respondents in the area report a riot) and 0 otherwise. The vector of regressors $Z_{n,(t-1)}$ includes a set of lagged neighbourhood characteristics, such as the presence of police station, temples, and a mosque in 2010. $\bar{X}_{n,(t-1)}$ is the set of within-neighbourhood means of the covariates, and $\mu_{n}$ is the random neighbourhood-level intercepts. All independent variables are 
summarized in Table A2 in the appendix. Standard errors are clustered at the neighbourhood level, which allows us to relax the assumption that standard errors are independent of each other within a given neighbourhood.

When reporting findings in the next section we report marginal effects for continuous independent variables and impact effects for binary independent variables, in order to ease interpretation. ${ }^{11}$ The marginal effect is interpreted as the effect (in probability points) of an infinitesimally small change in a continuous independent variable on the probability of a given social capital occurring at the sample averages of specified covariates. The impact effect gives the probability point increase (or 1/100 percentage point increase) in the probability of a given social capital occurring when the binary independent variable is equal to one and at the sample averages of specified covariates.

\section{5}

\section{Main results}

Table 2 shows the impact and marginal effects of the estimates of equation 3. The equation is estimated for three dependent variables: membership of an organization (column 1), trust towards neighbours (column 2), and participation in face-to-face discussions (column 3).

Membership in organizations: Column (1) shows that in riot-prone neighbourhoods (where at least 30 per cent of the respondents in that neighbourhood reported a riot), the respondent and their household members are 50 percentage points more likely to be part of a group or organization. None of the other respondent-, household-, or neighbourhood-level covariates, except the presence of a Hindu temple in the neighbourhood, produce significant effects on membership in community organizations.

Trust in neighbours: Riot exposure does not affect social trust, but Muslim and Marathi speaking households are, respectively, 53 and 51 percentage points more likely to trust their neighbours. In addition, households who rent (rather than own property) are 95 percentage points more likely to trust their neighbours. Neighbourhoods that are older are less trusting. As the proportion of Muslims and/or Marathi speakers increase in a given neighbourhood, trust towards neighbours decreases, suggesting that social heterogeneity (which we will investigate in more detail in the next section) may partly explain reduced levels of trust.

Participation in community discussions: Column (3) shows that households living in riot-prone neighbourhoods are 19 percentage points less likely to participate in face-to-face discussions. Young male respondents are more likely to report that they, or a member of their household, participate in neighbourhood discussions. Marathi speakers are 26 percentage points more likely to participate in discussions. Wealthier households are also more likely to join community discussions. The proportion of tenants (versus landowners) increases the likelihood of face-to-face discussions. A neighbourhood with a high proportion of Marathi speakers has low participation in discussions.

Overall the results show that riot exposure in 2010 results in higher levels of household participation in community organizations in 2012, but in lower levels of trust (albeit not statistically significant) and reduced engagement in face-to-face community discussions. Therefore, households exposed to riots increase bridging forms of social capital but experience a reduction in bonding social capital. These results support the argument of social competition under uncertainty discussed in Section 2: under the threat of violence, households might invest in building networks with other social groups by joining local

11 The marginal effect involves multiplying the estimated coefficient by the standard normal probability density function calculated at sample averages of the covariates. The impact effect is calculated as the difference in the cumulative distribution function when the binary variable equals 1 and 0 , both calculated at sample averages. 
organizations since neighbourhood organizations may facilitate access to valuable information as well as the coordination of collective action against adverse events, such as riots (Verba et al. 1993).

At the same time, riot-affected neighbourhoods experience a reduction in trust between neighbours, who are also less likely to contribute to face-to-face community discussions. This is not surprising given that riots in India have largely an ethnic dimension, often pitching different religious and caste groups against each other-groups that are found living side-by-side in slum areas. These results suggest that in contexts of informal urban settlements, where different social groups must live in close physical proximity, households may invest in between-group interaction mechanisms (like joining community organizations), even when experiencing reduced levels of trust and willingness to engage in face-to-face interactions.

One concern with the findings above is the extent to which they may be affected by possible selection bias. This is because changes in household and neighbourhood composition may lead to either an overor under-estimation of the results. If, for instance, households with less social capital left riot-affected neighbourhoods between survey rounds, then the results above could well be due to selective migration. As we discussed in Section 3, we were able to find 80.4 per cent of the original sample in 2012. This attrition rate compares favorably to other panels (Lee 2003), particularly since it is reasonable to expect high levels of population movements in slum areas. Nonetheless, this attrition rate may raise concerns about selection bias if those who dropped out of the sample are significantly different to those who have remained. To test this potential bias, Table A5 in the appendix compares the 2010 socioeconomic characteristics of those who were located in 2012 and those we were not able to resurvey. This serves as a simple check of parallel trends. We note that households who dropped out of the sample are less likely to have reported a riot and lived in neighbourhoods where households were less likely to report a riot. We also observe that households from less fractionalized and polarized neighbourhoods were more likely to drop out of the panel. In the analysis above, we controlled for these variables. In addition, we corrected for potential selection bias using a Heckman two stage regression as a robustness check and found results to remain largely similar. The added Heckman selection term was also insignificant. These results are reported in Tables A6 and A7 in the appendix and suggest that the results above are unlikely to be biased due to attrition and resulting selection. ${ }^{12}$

12 The first stage is a probit model, which predicts selection into the second wave of the survey. The regressors are the same as in the main analysis, with the addition of a set of variables likely to affect attrition: fear of traveling to the nearest town alone, fear of walking alone in the neighbourhood, poor amenities in the neighbourhood, feelings of safety among female household members in neighbourhood during the day and night, and reporting that the household would like to move if possible. For the second stage, we run the same regression as equation 3, but include the inverse-Mills ratio as one of the covariates. The coefficient for the inverse-Mills ratio is not significant in all specifications except at a low level of significance for the dependent variable of participating in community discussions. 
Table 2: Effect of riot on social capital

\begin{tabular}{|c|c|c|c|}
\hline & $\begin{array}{c}(1) \\
\text { Organization }\end{array}$ & $\begin{array}{l}\text { (2) } \\
\text { Trust }\end{array}$ & $\begin{array}{c}\text { (3) } \\
\text { Discussions }\end{array}$ \\
\hline At least $30 \%$ of neighbourhood witnessed a riot (d) & $\begin{array}{c}0.50^{* * *} \\
(0.17)\end{array}$ & $\begin{array}{l}-0.072 \\
(0.25)\end{array}$ & $\begin{array}{l}-0.19^{* *} \\
(0.087)\end{array}$ \\
\hline \multicolumn{4}{|l|}{ Respondent age and sex in 2012} \\
\hline Age of respondent & $\begin{array}{l}-0.0027 \\
(0.0035)\end{array}$ & $\begin{array}{l}-0.0029 \\
(0.0037)\end{array}$ & $\begin{array}{c}-0.0070^{* *} \\
(0.0030)\end{array}$ \\
\hline Sex of respondent $(1=$ Male $)(d)$ & $\begin{array}{l}0.13 \\
(0.13)\end{array}$ & $\begin{array}{c}0.046 \\
(0.099)\end{array}$ & $\begin{array}{c}0.18^{*} \\
(0.093)\end{array}$ \\
\hline Household is Muslim (d) & $\begin{array}{l}-0.23 \\
(0.20)\end{array}$ & $\begin{array}{l}0.53^{* *} \\
(0.24)\end{array}$ & $\begin{array}{l}0.26 \\
(0.18)\end{array}$ \\
\hline Household size & $\begin{array}{c}0.012 \\
(0.018)\end{array}$ & $\begin{array}{c}0.013 \\
(0.018)\end{array}$ & $\begin{array}{r}-0.0017 \\
(0.012)\end{array}$ \\
\hline Household rents house $(0=$ Owns) $(d)$ & $\begin{array}{l}0.038 \\
(0.16)\end{array}$ & $\begin{array}{l}0.29^{* *} \\
(0.13)\end{array}$ & $\begin{array}{l}-0.094 \\
(0.12)\end{array}$ \\
\hline Log of monthly income per capita & $\begin{array}{l}-0.065 \\
(0.082)\end{array}$ & $\begin{array}{c}-0.0098 \\
(0.081)\end{array}$ & $\begin{array}{l}0.18^{* * *} \\
(0.064)\end{array}$ \\
\hline Mother tongue is Marathi (d) & $\begin{array}{l}0.0054 \\
(0.15)\end{array}$ & $\begin{array}{c}0.51^{* * *} \\
(0.17)\end{array}$ & $\begin{array}{l}0.26^{* *} \\
(0.13)\end{array}$ \\
\hline Hhd belongs to predominant religion/caste group (d) & $\begin{array}{l}-0.13 \\
(0.13)\end{array}$ & $\begin{array}{l}-0.034 \\
(0.12)\end{array}$ & $\begin{array}{c}0.15 \\
(0.098)\end{array}$ \\
\hline \multicolumn{4}{|l|}{ Lagged neighbourhood level variables (2010) } \\
\hline Police station in neighbourhood (d) & $\begin{array}{l}-0.066 \\
(0.18)\end{array}$ & $\begin{array}{l}-0.033 \\
(0.11)\end{array}$ & $\begin{array}{c}0.063 \\
(0.099)\end{array}$ \\
\hline Chowk in neighbourhood (d) & $\begin{array}{c}0.30 \\
(0.21)\end{array}$ & $\begin{array}{l}-0.23 \\
(0.19)\end{array}$ & $\begin{array}{l}0.13 \\
(0.11)\end{array}$ \\
\hline Hindu temple in neighbourhood (d) & $\begin{array}{l}-0.44^{*} \\
(0.24)\end{array}$ & $\begin{array}{l}-0.11 \\
(0.23)\end{array}$ & $\begin{array}{l}0.041 \\
(0.12)\end{array}$ \\
\hline Mosque in neighbourhood (d) & $\begin{array}{l}-0.035 \\
(0.18)\end{array}$ & $\begin{array}{l}-0.22 \\
(0.15)\end{array}$ & $\begin{array}{l}-0.17^{*} \\
(0.095)\end{array}$ \\
\hline Market in neighbourhood (d) & $\begin{array}{l}0.051 \\
(0.17)\end{array}$ & $\begin{array}{c}0.17 \\
(0.13)\end{array}$ & $\begin{array}{l}-0.064 \\
(0.11)\end{array}$ \\
\hline \multicolumn{4}{|l|}{ Lagged neighbourhood level averages } \\
\hline Average respondent age & $\begin{array}{l}-0.0082 \\
(0.031)\end{array}$ & $\begin{array}{l}-0.031 \\
(0.024)\end{array}$ & $\begin{array}{l}0.0053 \\
(0.020)\end{array}$ \\
\hline$\%$ of male respondents & $\begin{array}{l}-0.46 \\
(0.88)\end{array}$ & $\begin{array}{l}-0.73 \\
(0.81)\end{array}$ & $\begin{array}{l}-0.16 \\
(0.50)\end{array}$ \\
\hline$\%$ of Muslim households & $\begin{array}{l}-0.28 \\
(0.63)\end{array}$ & $\begin{array}{l}-0.83^{*} \\
(0.43)\end{array}$ & $\begin{array}{l}-0.46 \\
(0.40)\end{array}$ \\
\hline Average household size & $\begin{array}{c}0.077 \\
(0.083)\end{array}$ & $\begin{array}{c}0.053 \\
(0.093)\end{array}$ & $\begin{array}{l}0.010 \\
(0.047)\end{array}$ \\
\hline$\%$ of households who are tenants & $\begin{array}{l}-0.99 \\
(1.14)\end{array}$ & $\begin{array}{l}-0.82 \\
(0.75)\end{array}$ & $\begin{array}{l}1.48^{*} \\
(0.79)\end{array}$ \\
\hline Average monthly income per capita & $\begin{array}{l}0.13 \\
(0.24)\end{array}$ & $\begin{array}{l}0.32^{*} \\
(0.19)\end{array}$ & $\begin{array}{l}-0.13 \\
(0.16)\end{array}$ \\
\hline$\%$ of Marathi speakers & $\begin{array}{c}0.22 \\
(0.68)\end{array}$ & $\begin{array}{c}-0.92^{* *} \\
(0.41)\end{array}$ & $\begin{array}{c}-0.82^{* *} \\
(0.42)\end{array}$ \\
\hline $\begin{array}{l}\text { Observations } \\
\text { Degrees of freedom } \\
\text { Chi-squared } \\
\text { Prob > chi2 } \\
\text { Number of clusters }\end{array}$ & $\begin{array}{c}853 \\
21.000 \\
97.799 \\
0.000 \\
45.000\end{array}$ & $\begin{array}{c}853 \\
21.000 \\
71.500 \\
0.000 \\
45.000\end{array}$ & $\begin{array}{c}853 \\
21.000 \\
181.845 \\
0.000 \\
45.000\end{array}$ \\
\hline
\end{tabular}

Notes: marginal effects, standard errors in parentheses. (d) for discrete change of dummy variable from 0 to 1 . ${ }^{*} p<0.1,{ }^{* *} p<0.05,{ }^{* * *} p<0.01$.

Source: authors' calculations based on MHLS 2010 and 2012. 
Following the discussion in Section 2, we analyse here how the effects identified in the previous section might be conditional on the social diversity of neighbourhoods and the salience of individual identities.

\subsection{Social diversity of neighbourhoods}

As discussed in Section 2, diverse neighbourhoods could be less resilient to the effects of riot exposure than more homogeneous neighbourhoods because neighbours in the latter areas might be more willing to come together in the face of adversity. Alternatively, social diversity may be a source of social cooperation, when different groups understand that peace is essential to their living together or that shared adversity may bring them together. Social capital may also be seen as a form of insurance, bridging across social divides. We measure the social composition of neighbourhood along two dimensions: levels of fractionalization and levels of polarization. We focus on two social groups relevant in the Indian context: religion and caste. ${ }^{13}$ In our sample, 54 per cent of respondents are Hindus, 39 per cent of respondents are Muslims and the rest are either Christians or Buddhists. The Indian government's Mandal commission (1978) classified existing sub-castes according to certain socioeconomic indicators, leading to four broad categories of the Hindu caste system: Scheduled Tribes (ST), Scheduled Caste (SC), Other Backward Castes (OBC) and other (or Forward Castes). 6.51 per cent of the sample is ST, 14.59 per cent SC, 34.96 per cent OBC and 43.94 per cent are 'other'.

Considering the social composition of each neighbourhood along both religion and caste group simultaneously will lead to multicollinearity because they are highly correlated. For this reason, we have combined religion and caste affiliations by considering Muslims (formally outside of the caste system) as an additional category to the Hindu caste system. This approach has been taken by scholars who have studied social diversity and heterogeneity in India (Banerjee and Somanathan 2007). According to this categorization, 4.97 per cent of the sample is ST, 11.19 per cent SC, 16.59 per cent OBC, 26.91 per cent 'other caste', and 40.34 per cent Muslim. This categorization is a slight simplification because, in reality, the caste system has adapted to apply to Indian Muslims. However, the social implications of this categorization are minimal and this strategy helps avoiding larger issues around multicollinearity. We measure within each neighbourhood levels of polarization and fractionalization along caste and religious dimensions, using the following indices developed by Esteban and Ray (2008):

$$
\begin{gathered}
F=\sum_{i} n_{i}\left(1-n_{i}\right)=1-\sum_{i} n_{i}^{2} \\
P=\sum_{i} n_{i}^{2}\left(1-n_{i}\right)
\end{gathered}
$$

$F$ refers to social fractionalization and $P$ is social polarization. $n_{i}$ is the share of the population in each neighbourhood belonging to each social group $i$ (ST, SC, OBC, other caste, and Muslim). $F$ can be interpreted as the probability that two individuals from a given neighbourhood belong to different social groups. The higher that $F$ is, the more fractionalized the neighbourhood is. $P$ measures the dominance of a certain social group in the neighbourhood, with higher values indicating higher levels of

13 While the jati (which corresponds to the narrow definition of a sub-caste) is also a relevant social group in India, this would have created 98 separate groups in our sample and neighbourhoods would still show similarly high levels of fractionalization. Therefore, we have estimated results for the main caste categories only. 
polarization. ${ }^{14}$ Both indices range between zero and one. High values of $F$ indicate a large number of small social groups that are evenly represented, and high values of $P$ indicates a more even distribution of the population between few groups (in the case of $P=1$, the population would be split equally between two groups).

Table A2 in the appendix provides summary statistics of these measures. In our sample, fractionalization ranges between zero (all households in neighbourhood belong to the same social group) and 0.78 . The average fractionalization is 0.53 . This means that, on average, there is a 53 per cent chance that two households picked at random are from different social groups. Polarization ranges from zero (all households belong to the same social group) to 0.93 . On average, a neighbourhood has a polarization index of 0.68 , which is considerably high.

In order to investigate how levels of fractionalization and polarization shape the relationship between riot exposure and social capital measures, we interacted the neighbourhood experience of a riot with these two measures, as represented in the following equation:

$$
\begin{array}{r}
P\left[S_{i, n, t}=1\right]=\Phi\left[\beta_{1} X_{i,(t-1)}+\beta_{2} R_{n,(t-1)}+\beta_{3} D_{n,(t-1)}+\beta_{4} Z_{n,(t-1)}\right. \\
\left.+\beta_{5}\left[R_{n,(t-1)} \times D_{n,(t-1)}\right]+\theta \bar{X}_{n,(t-1)}+\mu_{n}+{ }_{i}\right]
\end{array}
$$

The variable $D_{n,(t-1)}$ indicates the social diversity of the neighbourhood $n$, measured by either polarization or fractionalization of the social group. To avoid multicollinearity, polarization and fractionalization will be modeled in two separate regressions. Equation 4 is similar to equation 3, with the addition of an augmented interaction term between exposure to violence and pre-existing social diversity. Equation 4 estimates $\beta_{5}$, which can be interpreted as the effect of riots on social capital conditional on the social composition of the neighbourhood. Table A8 in the appendix shows the results of estimating equation 4 for three dependent variables: membership in an organization (columns 1 and 2), trust towards neighbours (columns 3 and 4), and participation in discussions (columns 5 and 6). Columns (1), (3), and (5) interact the riot variable with social fractionalization, and columns (2), (4), and (6) interact the riot variable with social polarization for each of the dependent variables.

It is important to keep in mind that $\beta_{5}$ does not represent an impact effect. Interpreting interaction terms in a non-linear framework such as a probit estimator is not straightforward, especially for continuous conditional variables. Therefore, we illustrate the main marginal/impact effects graphically in figures 2 to 4 .

14 The polarization index can account for parameters such as inter-group distance and group identity (see Esteban and Ray (2008)), but this is difficult to measure in India and is highly subjective. 
Figure 2: Impact effects of riot exposure on belonging to an organization conditional on:

(a) fractionalization

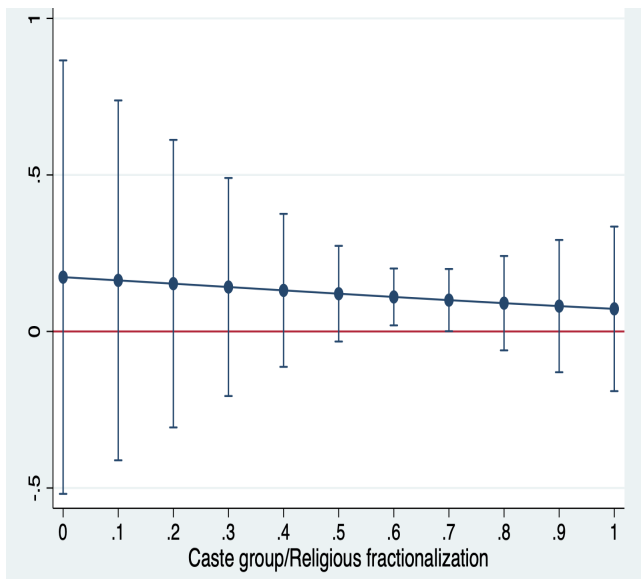

(b) polarization

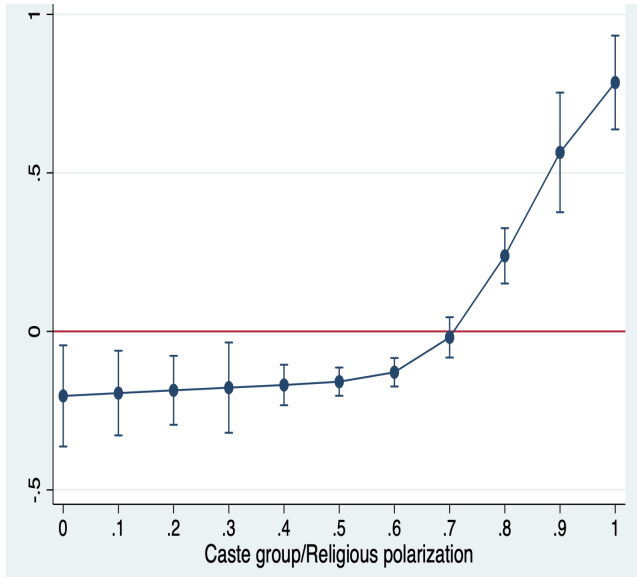

Source: authors' calculations based on MHLS 2010 and 2012.

Figure 3: Impact effects of riot exposure on trust in neighbours conditional on:

(a) fractionalization

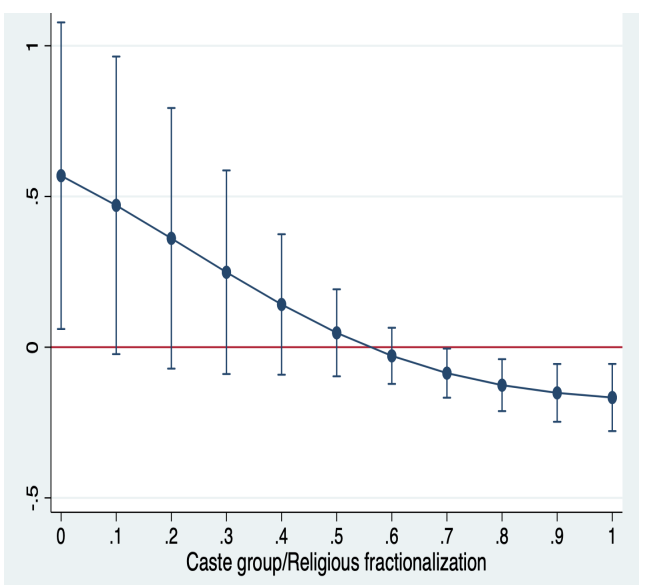

(b) polarization

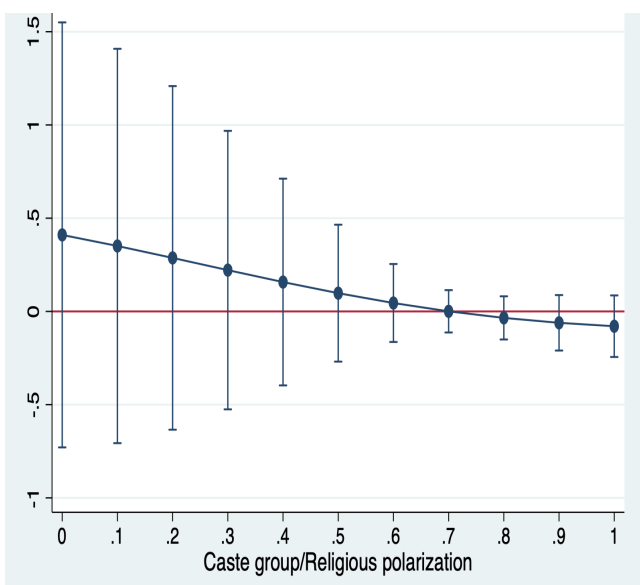

Source: authors' calculations based on MHLS 2010 and 2012.

Figure 4: Impact effects of riot exposure on participating in discussions conditional on:

(a) fractionalization

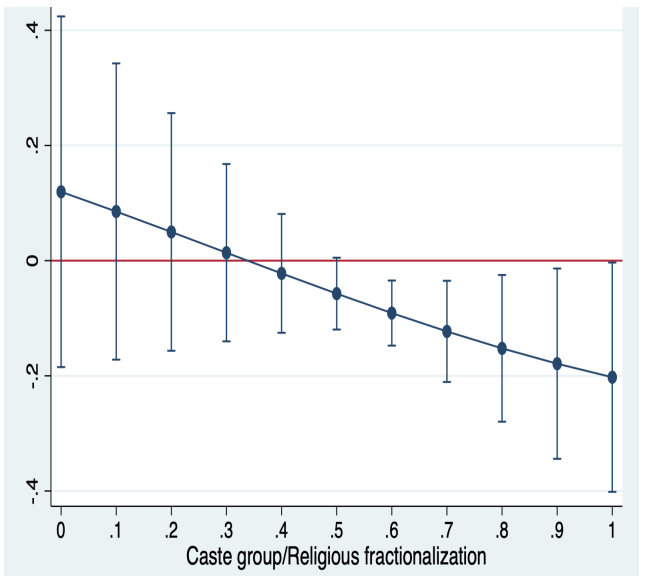

(b) polarization

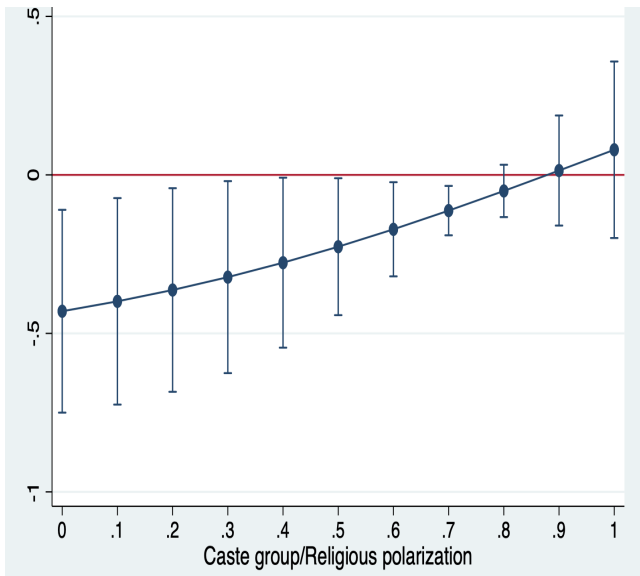

Source: authors' calculations based on MHLS 2010 and 2012. 
Membership in organizations: Figure 2a shows a positive effect (of around 10 percentage points) of riot exposure on the probability of being part of a civic group or organization when social group fractionalization is between 0.6 and 0.7. Conditional on polarization, the figure also shows that, in non-polarized neighbourhoods, riot exposure reduces the probability of belonging to an organization by 20.3 percentage points. As polarization increases, this effect becomes smaller. In highly polarized neighbourhoods, there is a positive effect of riot exposure on the probability of membership of local organizations, which reaches a maximum increase of 78.5 percentage points. While both of these conditional effects are measured at the extreme conditions of polarization that are unlikely to exist in most neighbourhoods, an important mechanism is revealed: social diversity can shape the effect of riot exposure on membership in organizations, creating a positive relationship in polarized or fractionalized neighbourhoods.

Trust in neighbours: Figure 3 a shows that, in less fractionalized neighbourhoods, riot exposure has a positive effect on social trust. There is a maximum increase of 56.8 percentage points in these neighbourhoods. In highly fractionalized neighbourhoods (when the index is greater than 0.7 ), the effect of riot becomes significant and negative: riot exposure reduces social trust by around 8.6 to 16.7 percentage points. The impact effect of riot exposure on the probability of trusting neighbours conditional on polarization is never significantly different than zero.

Participation in community discussions: Figure 4a shows that, in neighbourhoods where fractionalization is 0.4 and lower, exposure to riots increases participation in community discussions, but not in statistically significant way. When fractionalization is above 0.4 , there is a significantly negative effect of riot exposure on the probability of participating in a community discussion, ranging from -9.1 percentage points to -20.2 percentage points in completely fractionalized neighbourhoods. Figure $4 \mathrm{~b}$ shows that the effect of riots on the probability of participating in community discussions ranges from a negative effect in non-polarized neighbourhoods, to a positive (but insignificant) effect in polarized neighbourhoods. When polarization is lower than 0.7, the impact effect ranges from a 43 to 11.2 percentage point reduction, reducing when polarization increases.

Taken together, the results above suggest that social fractionalization and polarization have the potential to increase membership of organizations in riot-affected neighbourhoods. Social trust and face-to-face discussions are reduced in riot-affected neighbourhoods that are also highly socially fragmented. These results again reinforce our previous interpretation: households may be more likely to invest in bridging social capital and building networks with individuals and households from other social groups (by joining local community organizations) in communities that are more fragmented, and thus where the expectation of future riots may be higher. Households thus appear to invest in social capital in an instrumental way, possibly to mitigate future exposure.

Alternative explanations derived from social contact and post-traumatic growth theories may include more emotional and psychological factors, in that those living in riot-prone areas may join organizations as a way of seeking emotional support and solidarity from others that share similar experiences (Jennings 1999). However, the second set of results—that bonding social capital is reduced in riot-prone, fractionalized neighbourhoods-suggests that the instrumental explanation may be more accurate. Psychological arguments would lead to us observing also a positive effect of riots on more bonding forms of social capital. However, the data show that households in riot-prone fractionalized neighbourhoods are less likely to trust their neighbours and less likely to engage in face-to-face interactions.

We have tested the instrumentalization hypothesis further by disaggregating participation in community organizations according to whether the organization can be classified as co-ethnic (it includes members across all religions and castes) or not (it admits only members of one religion or caste). The underlying hypothesis is that interpretations aligned to social contact or post-traumatic growth theories would predict no statistically significant differences in participation across these categories of organizations. However, if the instrumental interpretation of social capital (predicted by theories of social competition 
under uncertainty) is correct, we should see stronger results among co-ethnic organizations. Table 3 shows that the main results we discussed above are strongly driven by co-ethnic organizations, which lends credibility to the argument that joining these organizations may be a means to bridge across social divides even if trust and confidence in neighbours may have been negatively affected.

Table 3: Effect of riot on belonging to a diverse group or organization

\begin{tabular}{lcc} 
& $(1)$ & $(2)$ \\
& & \\
& Diverse organization & Non-diverse organization \\
\hline At least $30 \%$ of neighbourhood witnessed a riot (d) & $0.53^{* * *}$ & 0.42 \\
& $(0.18)$ & $(0.75)$ \\
Respondent age and sex in 2012 & Yes & Yes \\
Lagged respondent and household variables (2010) & Yes & Yes \\
Lagged neighbourhood level variables (2010) & Yes & Yes \\
Lagged neighbourhood means of covariates & Yes & Yes \\
\hline Observations & 853 & 853 \\
Degrees of freedom & 21.000 & 21.000 \\
Chi-squared & 120.799 & 67.141 \\
Prob $>$ chi2 & 0.000 & 0.000 \\
Number of clusters & 45.000 & 45.000 \\
\hline
\end{tabular}

Notes: marginal effects, standard errors in parentheses. (d) for discrete change of dummy variable from 0 to 1 .

${ }^{*} p<0.1,{ }^{* *} p<0.05,{ }^{* * *} p<0.01$.

Source: authors' calculations based on MHLS 2010 and 2012.

There are compelling reasons why bonding social capital may be reduced in riot-prone neighbourhoods. It is possible that people are suspicious of others in the aftermath of riots and thus try to minimize daily face-to-face exchanges. Increase in suspicion against close neighbours has been reported in other riot instances (Hager et al. 2019) and in civil war contexts (Kalyvas 2006; Cassar et al. 2013). It is also possible that the reduction in face-to-face interactions may reflect discontent with others in the neighbourhood and even punishment and ostracizing of neighbours that may be blamed for prior exposure to riots (Petersen 2002). Both explanations are difficult to disentangle with the data we have available, but the results estimated above appear to support the suspicion explanation more strongly given the large reduction in trust in neighbours reported by households in riot-prone and highly fragmented neighbourhoods (recall that the effect of riot exposure on trust was not statistically significant in the overall sample).

We also tested whether the results above are due to social composition or may reflect relative social status of minority versus majority groups (Table 4). Studies have shown that group preferences, for instance about taxation (Xin Li 2010) or cultural outcomes (Bisin and Verdier 2001), may be shaped by whether the group is a minority or a majority group. In the case of India, Gupta et al. (2018) found that minority status is associated with positive in-group bias in social trust. We tested whether minority/majority status might affect the impact of riot exposure on social capital and found no statistically significant effects, suggesting that the social diversity effects above are not driven by relative social status but solely by the levels of social fragmentation and polarization that characterize different riot-exposed neighbourhoods. 
Table 4: Effect of riot interacted with belonging to major caste/religious group on social capital

\begin{tabular}{lccc}
\hline & $\begin{array}{c}(1) \\
\text { Organization }\end{array}$ & $\begin{array}{c}(2) \\
\text { Trust }\end{array}$ & $\begin{array}{c}(3) \\
\text { Discussions }\end{array}$ \\
\hline & & & \\
At least 30\% of neighbourhood witnessed & $0.41^{*}$ & -0.35 & -0.29 \\
a riot & $(0.21)$ & $(0.28)$ & $(0.24)$ \\
At least \%30 witnessed riot $\times$ & 0.16 & 0.45 & 0.16 \\
Household belongs to majority group & $(0.25)$ & $(0.36)$ & $(0.34)$ \\
Hhd belongs to predominant & -0.18 & -0.14 & 0.10 \\
religion/caste group & $(0.17)$ & $(0.13)$ & $(0.10)$ \\
Respondent age and sex in 2012 & Yes & Yes & Yes \\
Lagged respondent and household variables $(2010)$ & Yes & Yes & Yes \\
Lagged neighbourhood level variables (2010) & Yes & Yes & Yes \\
Lagged neighbourhood means of covariates & Yes & Yes & Yes \\
\hline Observations & 853 & 853 & 853 \\
Degrees of freedom & 22.000 & 22.000 & 22.000 \\
Chi-squared & 97.388 & 94.944 & 228.312 \\
Prob $>$ chi2 & 0.000 & 0.000 & 0.000 \\
Number of clusters & 45.000 & 45.000 & 45.000 \\
\hline
\end{tabular}

Notes: standard errors in parentheses. ${ }^{*} p<0.1,{ }^{* *} p<0.05,{ }^{* * *} p<0.01$.

Source: authors' calculations based on MHLS 2010 and 2012.

\subsection{Salience of individual identity}

Social identity has been widely documented as dominating social, economic, and political processes and decision-making in India, with different religious and caste groups exhibiting strong in-group biases (Gupta et al. 2018). Almost all major riots experienced in India since partition have been marked by divisions in social identity, particularly between Hindus and Muslims (Horowitz 2001; Wilkinson 2004). We therefore expect social identity to be an important factor in shaping the relationship between riot exposure and social capital in Maharashtra.

To investigate the effects of riot exposure on the salience of shared identities, we used a series of vignettes in the second wave of MHLS. Vignettes are 'short stories about hypothetical characters in specified circumstances, to whose situation the interviewee is invited to respond' Finch (1987, p. 105). The use of vignettes in surveys provides a useful research method to investigate respondents' beliefs, attitudes, and judgements (Atzmüller and Steiner 2010; Finch 1987; Nock and Rossi 1982; Seekings 2008), and by randomizing certain aspects of the context, it is possible to identify significant variables that explain certain beliefs.

While we could have directly asked the respondents for their opinions and attitudes towards people of the same or different identity, this strategy is unlikely to have elicited honest responses to such sensitive topics in Indian society. This could be due to social desirability biases, whereby respondents may want to impress the interviewers and respond in a way that they think will be socially approved of. Alternatively, normative factors that influence judgement may be subconscious so that the respondent is not aware of them (Alexander and Becker 1978). Vignettes may allow researchers to observe more accurate attitudes and beliefs by calculating average acceptance changes to a priori defined scenarios when key factors in the scenario are changed in a random way.

In our study, respondents were asked if they would be willing to give some money-INR3,000 (Rupees) or around US\$40 - to a person living in their neighbourhood, for a given reason. In order to study the salience of identities in household choices, we randomized the name of the person living in the neighbourhood. The person asking for the money was named in different versions of the vignette as 
Yadav, Hanif, or Deshpande. ${ }^{15}$ Yadav is a name typical to Hindus from OBC caste category, Hanif is a Muslim name and Deshpande is a typical Hindu upper caste name. ${ }^{16}$ For each respondent, we created a variable taking the value 1 if the identity of the respondent matches the identity of the person in the vignette and 0 otherwise.

We first tested whether the random assignment of the vignette characters created three groups from the sample that are roughly the same. Often studies have relied on a simple balance test of treatment and control groups to ensure random assignment, but in the case of three groups, this is slightly more cumbersome, and makes inference difficult. We tested first for differences in any of the covariates used in the analysis between Deshpande and Hanif, Deshpande and Yadav, and Hanif and Yadav. This resulted in 66 tests (22 covariates for each of these three combinations). Of these 66 tests, nine showed a statistically significant difference in covariates. This is a reasonable result given the large number of tests. In addition, we regressed each of these covariates ${ }^{17}$ on the character assignment, and then tested the joint significance of character assignment. ${ }^{18}$ The results of these orthogonality tests are shown in Table A9 in the appendix, which shows that character assignment is only a significant predictor of belonging to the majority caste or religious group, again a reasonable result. Finally, we regressed each character assignment on all the covariates and tested for joint significance of the covariates. ${ }^{19}$ These were found not to be significant predictors. These tests strongly indicate that the character assignment is random, providing an exogenous source of variation in the subsequent analysis. The dependent variable of interest is willingness to give money, which is equal to one if the respondent has said that they would be happy to offer money to the character in the vignette. We regress the willingness to give money on whether there is a shared identity between the vignette character and the respondent. We include the same household and neighbourhood level covariates (including neighbourhood means of household covariates) as in the analysis above. In addition, we include a variable indicating the character randomly assigned to the respondent:

$$
\begin{array}{r}
P\left[G_{i, n, t}=1\right]=\Phi\left[\alpha_{1} S I_{i,(t-1)}+\alpha_{2} C_{i,(t-1)}+\beta_{1} X_{i,(t-1)}\right. \\
\left.+\beta_{2} Z_{n,(t-1)}+\theta \bar{X}_{n,(t-1)}+\mu_{n}+{ }_{i}\right]
\end{array}
$$

This model also uses the probit function, $\Phi$, the inverse standard normal transformation of covariates. $P\left[G_{i, n, t}=1\right]$ is the probability of giving money to the character in the vignette, and $S I_{i,(t-1)}$ is a binary indicator taking the value 1 if there is a shared identity between the respondent and the character in the vignette, and 0 otherwise. $C_{i,(t-1)}$ is a set of two binary variables representing the character assignment (the variable indicating Yadav was omitted and acts as the base for comparison). $X_{i,(t-1)}$ are household characteristics, $Z_{n,(t-1)}$ neighbourhood level characteristics, and $\bar{X}_{n,(t-1)}$ are the neighbourhood level means of respondent and household characteristics.

Column (1) in Table 5 shows that a shared identity with the character in the vignette makes the respondent 23 percentage points more likely to give money to this character. We then explore whether the

15 We also randomized the reason for the money request between repaying a loan, bribing a local goon, or buying a festive saree. In this paper, we pool these three reasons for request of money together, as this dimension is not central to the research questions being addressed in the paper.

16 Dalits, or untouchables, are excluded from this analysis as they cannot identify with these identities to the same extent as the other groups.

17 For continuous variables we use a neighbourhood fixed effects OLS estimation, and for binary variables a neighbourhood fixed effect logit estimation.

18 The p-value of the F-statistic is recorded for continuous variables, whereas the p-value of the Chi-squared is recorded for binary variables.

19 This is using a neighbourhood fixed effect logit estimation, and joint significance is tested using a Chi-squared distribution. 
salience of shared identities is affected by riot exposure, by estimating the following equation:

$$
\begin{array}{r}
P\left[G_{i, n, t}=1\right]=\Phi\left[\beta_{1} R_{n,(t-1)}+\beta_{2}\left[R_{n,(t-1)} \times S I_{i,(t-1)}\right]+\alpha_{1} S I_{i,(t-1)}+\alpha_{2} C_{i,(t-1)}\right. \\
\left.+\beta_{3} X_{i,(t-1)}+\beta_{4} Z_{n,(t-1)}+\theta \bar{X}_{n,(t-1)}+\mu_{n}+{ }_{i}\right]
\end{array}
$$

In equation 6 the term of $R_{n,(t-1)} \times S I_{i,(t-1)}$ captures the interaction between riot exposure and shared identity. $\beta_{1}$ is the effect of riot exposure, and $\beta_{2}$ is the effect of riot exposure when the respondent shares the same identity as the character in the vignette.

Table 5: Dependent variable: willingness to give

\begin{tabular}{lcc}
\hline & $(1)$ & $(2)$ \\
& Riot & Riot $\times$ Match \\
\hline & & \\
At least 30\% of neighbourhood witnessed a riot & & -0.081 \\
& & $(0.20)$ \\
At least 30\% witnessed riot $\times$ Shared identity & & -0.15 \\
& & $(0.23)$ \\
Shared identity with vignette character & $0.23^{* *}$ & $0.26^{*}$ \\
& $(0.12)$ & $(0.14)$ \\
Assigned Hanif as character & -0.16 & -0.17 \\
& $(0.11)$ & $(0.11)$ \\
Assigned Deshpande as character & -0.072 & -0.083 \\
& $(0.099)$ & $(0.097)$ \\
Respondent age and sex in 2012 & Yes & Yes \\
Lagged respondent and household variables $(2010)$ & Yes & Yes \\
Lagged neighbourhood level variables (2010) & Yes & Yes \\
Lagged neighbourhood means of covariates & Yes & Yes \\
\hline Observations & 852 & 852 \\
Degrees of freedom & 23.000 & 25.000 \\
Prob $>$ chi2 & 94.986 & 177.255 \\
Number of clusters & 0.000 & 0.000 \\
\hline Notes: standard errs in parentheses* $p<0.000$ & 45.000 \\
\hline
\end{tabular}

Notes: standard errors in parentheses. ${ }^{*} p<0.1,{ }^{* *} p<0.05,{ }^{* * *} p<0.01$.

Source: authors' calculations based on MHLS 2010 and 2012.

Column (2) of Table 5 shows that the impact of shared identity on the willingness to give is driven by those who have not been affected by riots. Those who experience riots are not more likely to give money if their identity is shared with that in the vignette. This result may appear inconsequential but is of great significance in face of the enormous importance of social identities across all aspects of social,economic, and political life in India. This comparison shows that experiencing a riot substantially reduces the salience of social identity in inter-group exchanges in Maharashtra. This reinforces the argument that individuals from different social groups, forced to live side-by-side in slum areas, take actions to bridge across social divides to minimize the threat of future riots.

\section{Conclusion}

This study has explored the relationship between exposure to riots and social capital in informal urban settlements in India using a unique panel dataset. The results show that households living in neighbourhoods that experienced a riot in 2010 are more likely to be members of groups and organizations, but less likely to join in face-to-face discussions with neighbours. Further analysis shows that this result in driven by social fragmentation: increased membership of organizations is greatest in fragmented neighbourhoods.

We interpret these results as evidence for a precautionary mechanism adopted by competing co-ethnic groups living under uncertainty, whereby households insure themselves through investments in bridging 
social capital, even when riots lead to reductions in trust and confidence in neighbours. This result is further substantiated by a vignette analysis where we randomize pairing of social identities. We find that the salience of social identities—so important to life in India—disappears in riot-prone neighbourhoods, where households may be trying to establish a systems of reciprocity.

Riots are an endemic feature of life in urban India and many other developing countries where urbanization is rising in unprecedented ways. Beyond the physical and economic losses suffered by those affected, trust and face-to-face relations can also be destroyed in such polarized, fragmented, and violenceprone contexts. This analysis has shown that there is agency and thoughtful consideration in building some types of social capital, but this result raises a lot of new questions. Although it is widely accepted that bridging and associative forms of social capital are more relevant to peaceful inter-group relations than other more interpersonal relations (Putnam et al. 1994; Varshney 2002), how long can these associations be sustained in the absence of trust? Future research is needed to disentangle the complex ways in which different social groups relate when under the threat of violence, how new forms of urbanization may support or hinder such social interactions, what social, economic, and political order may emerge from these processes, and how this may expand into other areas of society as individuals graduate from slums into the formal economy, potentially bringing with them mistrust and fear into new relations, jobs, and political decisions.

\section{References}

Afridi, F., Li, S. X., and Ren, Y. (n.d.). 'Social identity and inequality: The impact of China's hukou system'. Journal of Public Economics, 123(C): 17-29. doi: 10.1016/j.jpubeco.2014.12.011

Akerlof, G. A., and Kranton, R. E. (2000, 08). 'Economics and Identity'. The Quarterly Journal of Economics, 115(3): 715-53. doi: 10.1162/003355300554881

Alesina, A., Baqir, R., and Easterly, W. (1999). 'Public goods and ethnic divisions'. The Quarterly Journal of Economics, 114(4): 1243-84. doi: 10.1162/003355399556269

Alesina, A., and La Ferrara, E. (2000). 'Participation in heterogeneous communities'. The Quarterly Journal of Economics, 115(3): 847-904. doi: 10.1162/003355300554935

Alesina, A., and La Ferrara, E. (2002). 'Who trusts others?' Journal of Public Economics, 85(2): 207-34. doi: 10.1016/S0047-2727(01)00084-6

Alesina, A., and La Ferrara, E. (2005). 'Ethnic diversity and economic performance'. Journal of Economic Literature, 43(3): 762-800. doi: 10.1257/002205105774431243

Alexander, C. S., and Becker, H. J. (1978). 'The use of vignettes in survey research'. Public opinion quarterly, 42(1): 93-104. doi: 10.1086/268432

Allport, G. W. (1954). The nature of prejudice. Cambridge, Mass: Addison-Wesley.

Atzmüller, C., and Steiner, P. M. (2010). 'Experimental vignette studies in survey research'. Methodology: European Journal of Research Methods for the Behavioral and Social Sciences, 6(3): 128-38. doi: 10.1027/1614-2241/a000014

Banerjee, A., and Somanathan, R. (2007). 'The political economy of public goods: Some evidence from India'. Journal of development Economics, 82(2): 287-314. doi: 10.1016/j.jdeveco.2006.04.005

Bardhan, P. (2005). Scarcity, conflicts, and cooperation. Cambridge, Massachusetts: MIT Press.

Bauer, M., Blattman, C., Chytilová, J., Henrich, J., Miguel, E., and Mitts, T. (2016). 'Can war foster cooperation?' Journal of Economic Perspectives, 30(3): 249-74. doi: 10.1257/jep.30.3.249

Bauer, M., Cassar, A., Chytilová, J., and Henrich, J. (2014). 'War's enduring effects on the development of egalitarian motivations and in-group biases'. Psychological science, 25(1): 47-57. doi: 10 $.1177 / 0956797613493444$

Beber, B., Roessler, P., and Scacco, A. (2014). 'Intergroup violence and political attitudes: evidence from a dividing Sudan'. The Journal of Politics, 76(3): 649-65. doi: 10.1017/ S0022381614000103 
Bellows, J., and Miguel, E. (2009). 'War and local collective action in Sierra Leone'. Journal of Public Economics, 93(11-12): 1144-57. doi: 10.1016/j.jpubeco.2009.07.012

Bisin, A., and Verdier, T. (2001). 'The economics of cultural transmission and the dynamics of preferences'. Journal of Economic theory, 97(2): 298-319. doi: 10.1006/jeth.2000.2678

Blattman, C. (2009). 'From violence to voting: War and political participation in Uganda'. American Political Science Review, 103(02): 231-47. doi: 10.1017/S0003055409090212

Bowles, S., and Gintis, H. (2011). A cooperative species: Human reciprocity and its evolution. Princeton: Princeton University Press.

Brass, P. R. (1997). Theft of an idol: Text and context in the representation of collective violence. Princeton: Princeton University Press.

Canetti-Nisim, D., Ariely, G., and Halperin, E. (2008). 'Life, pocketbook, or culture: The role of perceived security threats in promoting exclusionist political attitudes toward minorities in Israel'. Political Research Quarterly, 61(1): 90-103. doi: 10.1177/1065912907307289

Caria, A. S., and Fafchamps, M. (2019). 'Can people form links to efficiently access information?' (unpublished manuscript)

Caselli, F., and Coleman, W. J. (2013). 'On the theory of ethnic conflict'. Journal of the European Economic Association, 11(suppl_1): 161-92. doi: 10.1111/j.1542-4774.2012.01103.x

Cassar, A., Grosjean, P., and Whitt, S. (2013). 'Legacies of violence: trust and market development'. Journal of Economic Growth, 18(3): 285-318. doi: 10.1007/s10887-013-9091-3

Chamberlain, G. (1984). 'Panel data'. In Z. Griliches and M. Intriligator (eds), Handbook of econometrics (Vol. 2, pp. 1247-1318). Amsterdam: Elsevier. doi: 10.1016/S1573-4412(84)02014-6

Chen, Y., and Li, S. X. (2009). 'Group identity and social preferences'. American Economic Review, 99(1): 431-57. doi: 10.1257/aer.99.1.431

Collins, W. J., and Margo, R. A. (2007). 'The economic aftermath of the 1960s riots in American cities: Evidence from property values'. The Journal of Economic History, 67(4): 849-83. doi: $10.1017 /$ S0022050707000423

Corno, L., La Ferrara, E., and Burns, J. (2019). 'Interaction, stereotypes and performance: Evidence from South Africa'. IFS Working Paper W19/03. London: Institute for Fiscal Studies. doi: 10.1920/wp.ifs.2019.0319

Côté, R. R., Andersen, R., and Erickson, B. H. (2015). 'Social capital and ethnic tolerance: the opposing effects of diversity and competition'. In Handbook of research methods and applications in social capital. Cheltenham: Edward Elgar Publishing.

Dasgupta, P., and Serageldin, I. (eds). (2002). Social capital: A multifaceted perspective. Washington, D.C.: The World Bank.

Davis, D. W., and Silver, B. D. (2004). 'Civil liberties vs. security: Public opinion in the context of the terrorist attacks on america'. American Journal of Political Science, 48(1): 28-46. doi: $10.1111 / \mathrm{j} .0092-5853.2004 .00054 . \mathrm{x}$

Deaton, A., and Dreze, J. (2002). 'Poverty and inequality in India: A re-examination'. Economic and Political Weekly, 37(36): 3729-48. Retrieved from http://www.jstor.org/stable/4412578 (accessed 2 May 2016)

DiPasquale, D., and Glaeser, E. L. (1998). 'The Los Angeles riot and the economics of urban unrest'. Journal of Urban Economics, 43(1): 52-78. doi: 10.1006/juec.1996.2035

DiPasquale, D., and Glaeser, E. L. (1999). 'Incentives and social capital: Are homeowners better citizens?' Journal of Urban Economics, 45(2): 354-84. doi: 10.1006/juec.1998.2098

Esteban, J., and Ray, D. (2008). 'Polarization, fractionalization and conflict'. Journal of Peace Research, 45(2): 163-82. doi: 10.1177/0022343307087175

Fafchamps, M., and Gubert, F. (2007). 'The formation of risk sharing networks'. Journal of development Economics, 83(2): 326-50. doi: 10.1016/j.jdeveco.2006.05.005

Finch, J. (1987). 'The vignette technique in survey research'. Sociology, 21(1): 105-14. doi: 10.1177/ 0038038587021001008 
Forbes, H. D. (1997). Ethnic conflict: Commerce, culture, and the contact hypothesis. New Haven: Yale University Press.

Gilligan, M. J., Pasquale, B. J., and Samii, C. (2014). 'Civil war and social cohesion: Lab-in-the-field evidence from Nepal'. American Journal of Political Science, 58(3): 604-19. doi: 10.1111/ ajps. 12067

Glaeser, E. L., Laibson, D., and Sacerdote, B. (2002). 'An economic approach to social capital'. Economic Journal, 112(483): 437-58. doi: 10.1111/1468-0297.00078

Gould, E. D., and Klor, E. F. (2010). 'Does terrorism work?' The Quarterly Journal of Economics, 125(4): 1459-510. doi: 10.1162/qjec.2010.125.4.1459

Grootaert, C., and van Bastelaer, T. (2002). Understanding and measuring social capital: A multidisciplinary tool for practitioners. Washington, D.C.: World Bank.

Gupta, G., Mahmud, M., Maitra, P., Mitra, S., and Neelim, A. (2018). 'Religion, minority status, and trust: Evidence from a field experiment'. Journal of Economic Behavior \& Organization, 146(-): 180-205. doi: 10.1016/j.jebo.2017.11.028

Gupte, J., Justino, P., and Tranchant, J.-P. (2014). 'Households amid urban riots the economic consequences of civil violence in India'. Journal of Conflict Resolution, 58(8): 1445-73. doi: $10.1177 / 0022002714547886$

Habyarimana, J., Humphreys, M., Posner, D. N., and Weinstein, J. M. (2007). 'Why does ethnic diversity undermine public goods provision?' American Political Science Review, 101(4): 709. doi: $10.1017 /$ S0003055407070499

Hager, A., Krakowski, K., and Schaub, M. (2019). 'Ethnic riots and prosocial behavior: Evidence from Kyrgyzstan'. American Political Science Review, 113(4): 1029-44. doi: 10.1017/ S000305541900042X

Hoff, K., and Pandey, P. (2006). 'Discrimination, social identity, and durable inequalities'. American Economic Review, 96(2): 206-11.

Horowitz, D. L. (2000). Ethnic groups in conflict, updated edition with a new preface. Berkeley: University of California Press.

Horowitz, D. L. (2001). The deadly ethnic riot. Berkeley: University of California Press.

Huddy, L., Feldman, S., Taber, C., and Lahav, G. (2005). 'Threat, anxiety, and support of antiterrorism policies'. American journal of political science, 49(3): 593-608. doi: 10.1111/j.1540-5907.2005 .00144.x

Iyer, S. (2016). 'The new economics of religion'. Journal of Economic Literature, 54(2): 395-441. doi: $10.1257 / \mathrm{jel} .54 .2 .395$

Jaffrelot, C. (2007). 'The 2002 pogrom in Gujarat: the post-9/11 face of Hindu nationalist anti-Muslim violence'. In J. R. Hinnells and R. King (eds), Religion and violence in south asia. theory and practice (pp. 69-77). London: Routledge.

Jennings, M. K. (1999). 'Political responses to pain and loss presidential address, american political science association, 1998'. American Political Science Review, 93(1): 1-13. doi: 10.2307/2585757

Jha, S. (2013). 'Trade, institutions, and ethnic tolerance: Evidence from South Asia'. American political Science review, 107(4): 806-32. doi: 10.1017/S0003055413000464

Kalyvas, S. N. (2006). The logic of violence in civil war. Cambridge: Cambridge University Press.

Katzenstein, M. F. (1989). 'Organizing against violence: Strategies of the Indian women's movement'. Pacific Affairs, 62(1): 53-71. doi: 10.2307/2760264

Kishi, R., and Pavlik, M. (2019). ACLED 2018 the year in review. Armed Conflict Location and Event Data Project (ACLED).

Knack, S., and Keefer, P. (1997). 'Does social capital have an economic payoff? A cross-country investigation'. The Quarterly Journal of Economics, 112(4): 1251-88. doi: 10.1162/003355300555475

Lee, U. (2003). 'Panel attrition in survey data: a literature review'. CSSR Working Paper 41. Cape Town: Centre for Social Science Research, University of Cape Town. doi: 11427/20156

Lyall, J. (2009). 'Does indiscriminate violence incite insurgent attacks? Evidence from Chechnya'. Journal of Conflict Resolution, 53(3): 331-62. doi: 10.1177/0022002708330881 
Mazumdar, D. (1987). 'Rural-urban migration in developing countries'. In Urban economics (Vol. 2, pp. 1097-128). Amsterdam: Elsevier. doi: 10.1016/S1574-0080(87)80014-7

Miguel, E., and Gugerty, M. K. (2005). 'Ethnic diversity, social sanctions, and public goods in Kenya'. Journal of public Economics, 89(11): 2325-68. doi: 10.1016/j.jpubeco.2004.09.004

Mundlak, Y. (1978). 'On the pooling of time series and cross section data'. Econometrica: journal of the Econometric Society, 46(1): 69-85. doi: 10.2307/1913646

Narayan, D., and Pritchett, L. (1999). 'Cents and sociability: Household income and social capital in rural Tanzania'. Economic development and cultural change, 47(4): 871-97. doi: 10.1086/ 452436

Nock, S. L., and Rossi, P. H. P. H. (1982). Measuring social judgments : the factorial survey approach. Thousand Oaks: Sage.

Nunn, N., and Wantchekon, L. (2011). 'The slave trade and the origins of mistrust in Africa'. American Economic Review, 101(7): 3221-52. doi: 10.1257/aer.101.7.3221

Paluck, E. L., Green, S. A., and Green, D. P. (2019). 'The contact hypothesis re-evaluated'. Behavioural Public Policy, 3(2): 129-58. doi: 10.1017/bpp.2018.25

Petersen, R. D. (2002). Understanding ethnic violence: Fear, hatred, and resentment in twentiethcentury Eastern Europe. Cambridge: Cambridge University Press.

Portes, A. (1998). 'Social capital: Its origins and applications in modern sociology'. Annual Review of Sociology, 24(-): 1-24. doi: 10.1146/annurev.soc.24.1.1

Putnam, R. D. (2000). Bowling alone: The collapse and revival of the American community. New York: Simon and Schuster Paperbacks.

Putnam, R. D., Leonardi, R., and Nanetti, R. (1994). Making democracy work: civic traditions in modern Italy. Princeton: Princeton University Press.

Seekings, J. (2008). 'The continuing salience of race: Discrimination and diversity in South Africa'. Journal of contemporary African studies, 26(1): 1-25. doi: 10.1080/02589000701782612

Spater, J. (2019). 'Exposure and preferences: Evidence from Indian slums'. (unpublished manuscript)

Tajfel, H. (ed.). (1978). Differentiation between social groups: Studies in the social psychology of intergroup relations. New York: Academic Press.

Tajfel, H., Billig, M. G., Bundy, R. P., and Flament, C. (1971). 'Social categorization and intergroup behaviour'. European journal of social psychology, 1(2): 149-78. doi: 10.1002/ejsp.2420010202

Tedeschi, R. G., and Calhoun, L. G. (2004). 'Post-traumatic Growth: Conceptual foundations and empirical evidence'. Psychological inquiry, 15(1): 1-18. doi: 10.1207/s15327965pli1501_01

UN-Habitat. (2003). The challenge of slums: Global report on human settlements. Nairobi: United Nations Human Settlements Programme.

Varshney, A. (2001). 'Ethnic conflict and civil society: India and beyond'. World Politics, 53(3): 362-98. doi: 10.1353/wp.2001.0012

Varshney, A. (2002). Ethnic conflict and civic life: Hindus and Muslims in India. New Haven: Yale University Press.

Verba, S., Schlozman, K. L., Brady, H., and Nie, N. H. (1993). 'Citizen activity: Who participates? what do they say?' American Political Science Review, 87(2): 303-18. doi: 10.2307/2939042

Vigdor, J. L. (2004). 'Community composition and collective action: Analyzing initial mail response to the 2000 census'. Review of Economics and Statistics, 86(1): 303-12. doi: 10.1162/ 003465304323023822

Voors, M. J., Nillesen, E. E. M., Verwimp, P., Bulte, E. H., Lensink, R., and Van Soest, D. P. (2012). 'Violent conflict and behavior: A field experiment in Burundi'. American Economic Review, 102(2): 941-64. doi: 10.1257/aer.102.2.941

Wilkinson, S. I. (2004). Votes and violence: Ethnic competition and ethnic riots in India. Cambridge: Cambridge University Press.

Wilkinson, S. I. (2005). 'Communal riots in India'. Economic and Political Weekly, 40(44/45): 476870. 
Wilkinson, S. I. (2009). 'Riots'. Annual Review of Political Science, 12(1): 329-43. doi: 10.1146/ annurev.polisci.12.041307.075517

Xin Li, S. (2010). 'Social identities, ethnic diversity, and tax morale'. Public Finance Review, 38(2): 146-77. doi: 10.1177/1091142110369239 


\section{Appendix: tables and figures}

Figure A1: Riots in Maharashtra

\section{Number of riots}

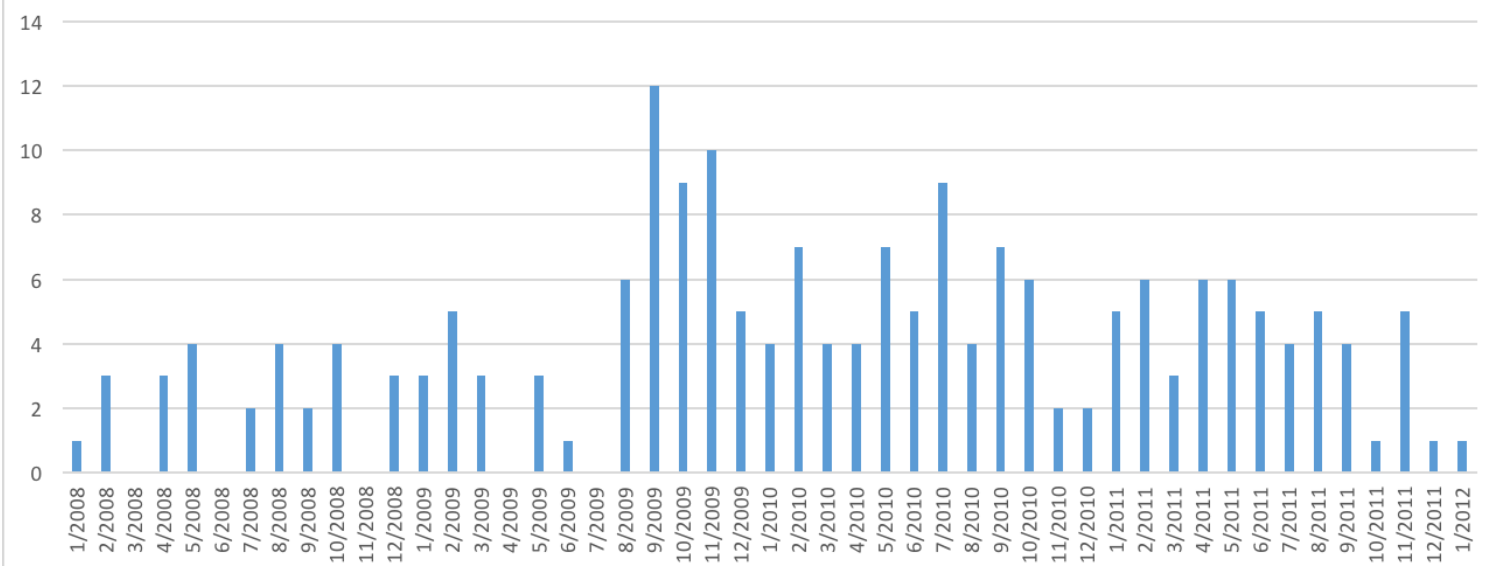

Note: number of riots per month, from January 2008 to January 2012.

Source: authors' compilation after scanning local newspapers. 
Figure A2: Effect of riot exposure on social capital when using different cut-offs for neighbourhood level riots

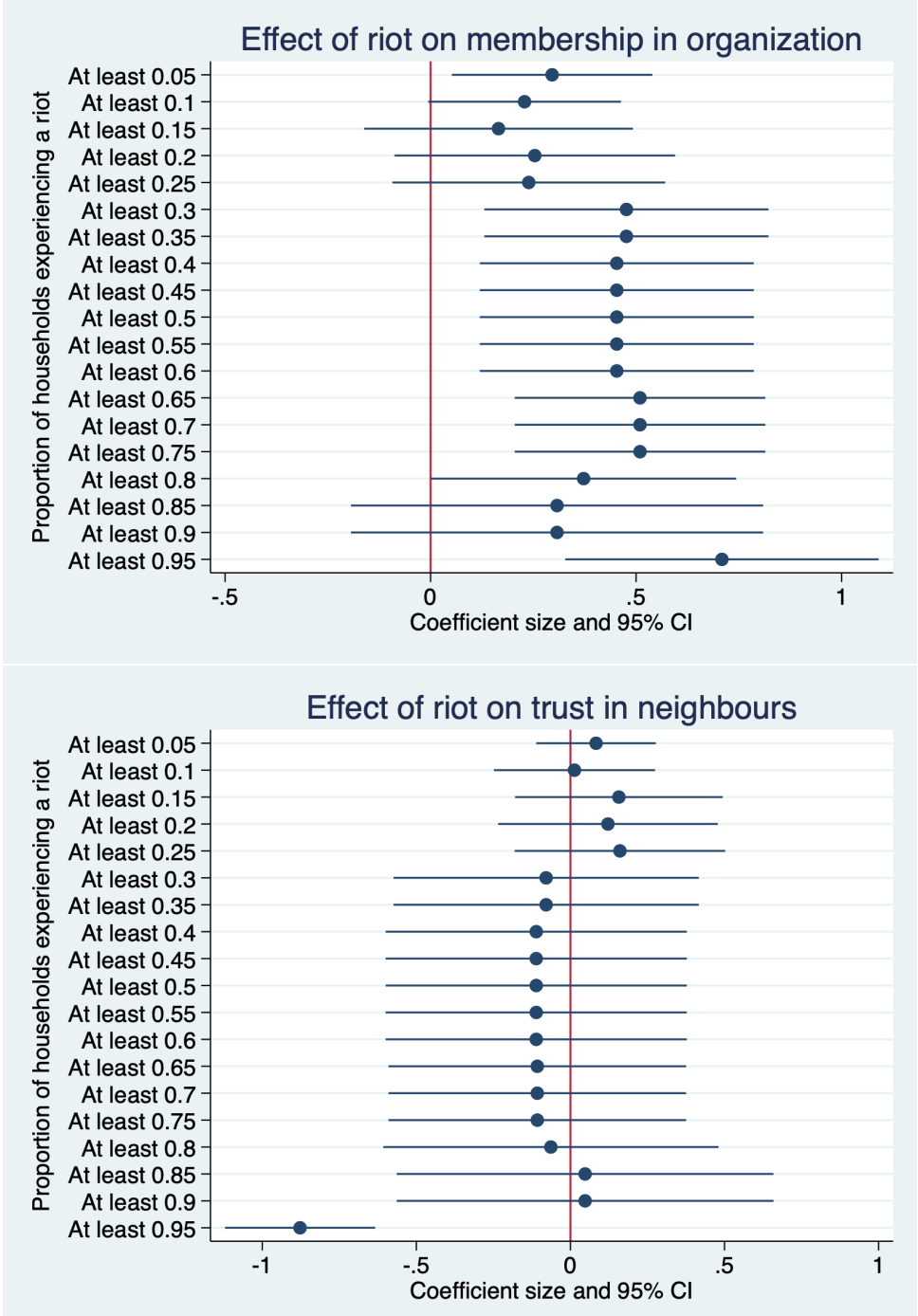

Effect of riot on participation in community discussions

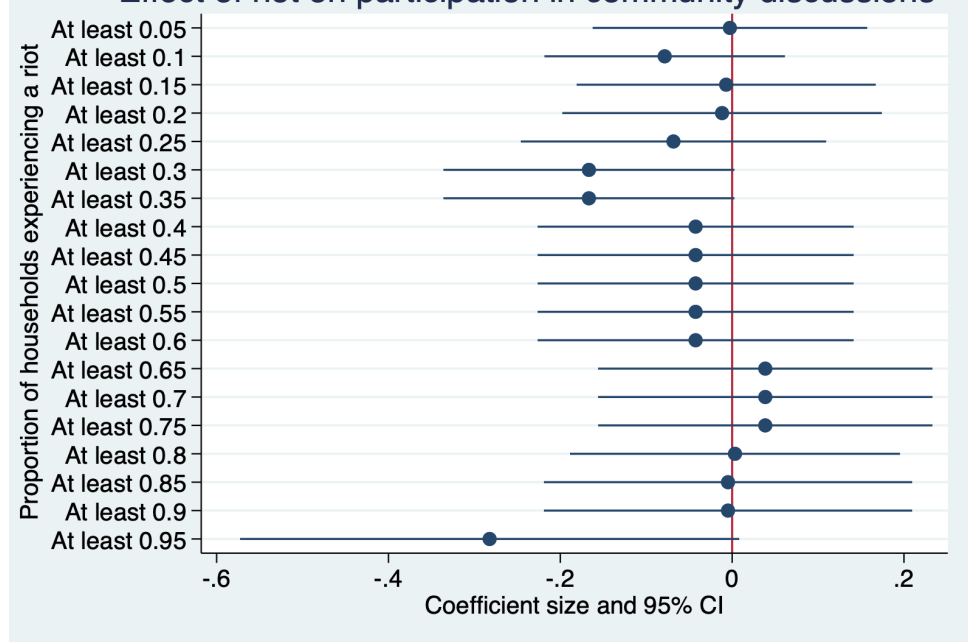

Source: authors' calculations based on MHLS 2010 and 2012. 
Table A1: Summary statistics of newspaper reported riot data

\begin{tabular}{lccccc}
\hline \multicolumn{1}{c}{ Variable } & Mean & Std. dev. & Min. & Max. & N \\
\hline Duration of riot in days & 1.111 & 0.802 & 1 & 12 & 225 \\
At least one civilian was injured & 0.427 & 0.496 & 0 & 1 & 225 \\
At least one civilian was killed & 0.076 & 0.265 & 0 & 1 & 225 \\
At least one policeman was injured & 0.173 & 0.379 & 0 & 1 & 225 \\
At least one policeman was killed & 0 & 0 & 0 & 0 & 225 \\
An arrest or charge was made & 0.258 & 0.438 & 0 & 1 & 225 \\
Number of charges & 1.298 & 6.817 & 0 & 61 & 225 \\
Number of arrests & 11.924 & 71.503 & 0 & 1000 & 225 \\
Police engaged in violence against civilians & 0.249 & 0.433 & 0 & 1 & 225 \\
A curfew was enforced due to the riot & 0.089 & 0.285 & 0 & 1 & 225 \\
The riot spread to neighbouring towns/communities & 0.044 & 0.207 & 0 & 1 & 225 \\
There was a communal element to the riot & 0.569 & 0.496 & 0 & 1 & 225 \\
The riot initiated from a personal dispute & 0.209 & 0.407 & 0 & 1 & 225 \\
The riot was initiated by a rumor & 0.027 & 0.161 & 0 & 1 & 225 \\
The riot initiated from a protest & 0.164 & 0.372 & 0 & 1 & 225 \\
The riot initiated from a Raasta roko & 0.058 & 0.234 & 0 & 1 & 225 \\
The riot was initiated by a slum demolition (attempted or & 0.031 & 0.174 & 0 & 1 & 225 \\
completed) & & & & & \\
The riot was related to an election & 0.089 & 0.285 & 0 & 1 & 225 \\
The riot involved a Bandh & 0.071 & 0.258 & 0 & 1 & 225 \\
The riot caused physical damage to public or private & 0.262 & 0.441 & 0 & 1 & 225 \\
property & & & & & \\
\hline Modality of violence & & & & & \\
\hline Stone throwing & & & & 1 & 225 \\
Bottle throwing & 0.511 & 0.501 & 0 & 1 & 225 \\
Physical fight & 0.027 & 0.161 & 0 & 1 & 225 \\
Physical attack & 0.271 & 0.446 & 0 & 1 & 225 \\
Physical beating & 0.067 & 0.25 & 0 & 1 & 225 \\
Physical scuffle & 0.062 & 0.242 & 0 & 1 & 225 \\
Arson & 0.04 & 0.196 & 0 & 1 & 225 \\
Vandalism & 0.084 & 0.279 & 0 & 1 & 225 \\
Looting & 0.08 & 0.272 & 0 & 1 & 225 \\
Tire burning & 0.013 & 0.115 & 0 & 1 & 225 \\
\hline & 0.004 & 0.067 & 0 & 1 & 225 \\
\hline
\end{tabular}

Source: authors' calculations after scanning local newspapers. 
Table A2: Summary statistics of independent variables in 2010.

\begin{tabular}{lccccc}
\hline \multicolumn{1}{c}{ Variable } & Mean & Std. dev. & Min. & Max. & N \\
\hline Household/Respondent level variables & & & & & \\
& & & & & \\
\hline Report riot taking place in neighbourhood & 0.235 & 0.424 & 0 & 1 & 867 \\
Age of respondent & 39.13 & 13.34 & 15 & 90 & 874 \\
Sex of respondent (1=Male) & 0.375 & 0.484 & 0 & 1 & 874 \\
Permanent house materials & 0.527 & 0.5 & 0 & 1 & 867 \\
Household is Muslim & 0.386 & 0.487 & 0 & 1 & 867 \\
Household size & 6.562 & 3.369 & 1 & 26 & 867 \\
Household rents house (0=Owns) & 0.133 & 0.339 & 0 & 1 & 867 \\
Log of monthly income per capita & 6.841 & 0.75 & 4.711 & 11.027 & 854 \\
Mother tongue is Marathi & 0.509 & 0.5 & 0 & 1 & 867 \\
Months lived in current house & 18.984 & 14.282 & 0 & 65 & 859 \\
There is an unsafe location nearby & 0.099 & 0.299 & 0 & 1 & 867 \\
Hhd belongs to predominant religion/caste group & 0.621 & 0.486 & 0 & 1 & 867 \\
\hline Neighbourhood level variables & & & & & \\
\hline At least 30\% of neighbourhood report a riot & & & & & \\
Proportion of households migrated by 2012 & 0.2 & 0.405 & 0 & 1 & 45 \\
Police station in neighbourhood & 0.111 & 0.065 & 0 & 0.261 & 45 \\
Chowk in neighbourhood & 0.4 & 0.418 & 0 & 1 & 45 \\
Hindu temple in neighbourhood & 0.489 & 0.506 & 0 & 1 & 45 \\
Mosque in neighbourhood & 0.378 & 0.49 & 0 & 1 & 45 \\
Market in neighbourhood & 0.2 & 0.405 & 0 & 1 & 45 \\
Caste group/Religious fractionalization & 0.526 & 0.217 & 0 & 0.778 & 45 \\
Caste group/Religious polarization & 0.678 & 0.217 & 0 & 0.932 & 45 \\
Religious polarization & 0.613 & 0.282 & 0 & 1 & 45 \\
Religious fractionalization & 0.342 & 0.174 & 0 & 0.635 & 45 \\
Caste group polarization & 0.834 & 0.09 & 0.445 & 0.992 & 45 \\
Caste group fractionalization & 0.584 & 0.104 & 0.244 & 0.727 & 45 \\
Caste polarization & 0.496 & 0.118 & 0.281 & 0.806 & 45 \\
Caste fractionalization & 0.827 & 0.069 & 0.583 & 0.922 & 45 \\
\hline Source: MHLS & & & & &
\end{tabular}

Source: MHLS 2010.

Table A3: Description of social capital variables as found in MHLS 2012 questionnaire

\begin{tabular}{|c|c|}
\hline Variable & Description from questionnaire \\
\hline $\begin{array}{l}\text { Household member belongs to } \\
\text { an organization }\end{array}$ & $\begin{array}{l}\text { Are you or any other household member a member of the following groups or } \\
\text { organizations? (Political party; Trade union; Student organization; Farmer's or- } \\
\text { ganization; Cooperative; Sports/cultural organization; Gym; Women's group; Lo- } \\
\text { cal Mohalla committee; Caste Panchayat/Sabha/association; Religious organi- } \\
\text { zations; Youth organization; Village redressial committee; Other group or orga- } \\
\text { nization) }\end{array}$ \\
\hline Trust towards neighbours & $\begin{array}{l}\text { Would you trust your money or assets for safekeeping with your neighbours (Yes; } \\
\text { No) }\end{array}$ \\
\hline $\begin{array}{l}\text { Household participates in com- } \\
\text { munity discussions }\end{array}$ & $\begin{array}{l}\text { How common is it that you or a family member participates in a community dis- } \\
\text { cussion? (All the time; Sometimes; Never) }\end{array}$ \\
\hline
\end{tabular}

Source: MHLS 2012

Table A4: Summary statistics of social capital variables.

\begin{tabular}{lccccc}
\hline \multicolumn{1}{c}{ Variable } & Mean & Std. dev. & Min. & Max. & N \\
\hline Household member belongs to an organization & 0.159 & 0.366 & 0 & 1 & 1088 \\
Trust towards neighbours & 0.171 & 0.377 & 0 & 1 & 1087 \\
Household participates in community discussions & 0.421 & 0.494 & 0 & 1 & 1088 \\
\hline
\end{tabular}

Source: MHLS 2012. 
Table A5: Differences of 2010 characteristics of tracked and not tracked households

\begin{tabular}{|c|c|c|c|}
\hline \multirow[b]{2}{*}{ Variable } & \multicolumn{2}{|c|}{ Mean } & \multirow[b]{2}{*}{ Diff. } \\
\hline & Tracked & Not tracked & \\
\hline Household member belongs to an organization & 0.14 & 0.10 & 0.04 \\
\hline Trust towards neighbours & $\begin{array}{c}(0.01) \\
0.4 \\
(0.02)\end{array}$ & $\begin{array}{c}(0.02) \\
0.29 \\
(0.03)\end{array}$ & $\begin{array}{c}(0.03) \\
0.11 \\
(0.04)\end{array}$ \\
\hline Report a riot taking place in neighbourhood & $\begin{array}{c}0.24 \\
(0.01)\end{array}$ & $\begin{array}{l}0.16 \\
(0.03)\end{array}$ & $\begin{array}{l}0.07^{* *} \\
(0.03)\end{array}$ \\
\hline At least $30 \%$ report a riot in neighbourhood & $\begin{array}{l}j 0.21 \\
(0.01)\end{array}$ & $\begin{array}{c}0.15 \\
(0.02)\end{array}$ & $\begin{array}{l}0.06^{*} \\
(0.03)\end{array}$ \\
\hline Caste group/Religious fractionalization & $\begin{array}{c}0.54 \\
(0.01)\end{array}$ & $\begin{array}{c}0.49 \\
(0.02)\end{array}$ & $\begin{array}{c}0.04^{* * * *} \\
(0.02)\end{array}$ \\
\hline Caste group/Religious polarization & $\begin{array}{c}0.69 \\
(0.01)\end{array}$ & $\begin{array}{c}0.64 \\
(0.02)\end{array}$ & $\begin{array}{c}0.05^{* * *} \\
(0.02)\end{array}$ \\
\hline Age of respondent & $\begin{array}{l}34.05 \\
(0.35)\end{array}$ & $\begin{array}{l}32.77 \\
(0.69)\end{array}$ & $\begin{array}{l}1.27 \\
(0.79)\end{array}$ \\
\hline Sex of respondent (1=Male) & $\begin{array}{c}0.34 \\
(0.02)\end{array}$ & $\begin{array}{c}0.32 \\
(0.03)\end{array}$ & $\begin{array}{c}0.03 \\
(0.04)\end{array}$ \\
\hline Permanent house materials & $\begin{array}{c}0.53 \\
(0.02)\end{array}$ & $\begin{array}{c}0.66 \\
(0.03)\end{array}$ & $\begin{array}{c}-0.13^{* * *} \\
(0.04)\end{array}$ \\
\hline Household is Muslim & $\begin{array}{c}0.39 \\
(0.02)\end{array}$ & $\begin{array}{c}0.41 \\
(0.03)\end{array}$ & $\begin{array}{l}-0.03 \\
(0.04)\end{array}$ \\
\hline Household size & $\begin{array}{l}6.55 \\
(0.11)\end{array}$ & $\begin{array}{l}4.82 \\
(0.13)\end{array}$ & $\begin{array}{c}1.74^{* * * *} \\
(0.24)\end{array}$ \\
\hline Household rents house ( $0=$ Owns) & $\begin{array}{c}0.14 \\
(0.01)\end{array}$ & $\begin{array}{c}0.41 \\
(0.03)\end{array}$ & $\begin{array}{c}-0.27^{* * *} \\
(0.03)\end{array}$ \\
\hline Log of monthly income per capita & $\begin{array}{c}6.84 \\
(0.03)\end{array}$ & $\begin{array}{l}7.19 \\
(0.05)\end{array}$ & $\begin{array}{c}-0.34^{* * *} \\
(0.06)\end{array}$ \\
\hline Mother tongue is Marathi & $\begin{array}{c}0.51 \\
(0.02)\end{array}$ & $\begin{array}{c}0.44 \\
(0.03)\end{array}$ & $\begin{array}{l}0.07^{*} \\
(0.04)\end{array}$ \\
\hline There is an unsafe location nearby & 0.1 & 0.07 & 0.02 \\
\hline Hhd belongs to predominant religion/caste group & $\begin{array}{c}(0.01) \\
0.62 \\
(0.02)\end{array}$ & $\begin{array}{c}(0.02) \\
0.65 \\
(0.03)\end{array}$ & $\begin{array}{l}(0.02) \\
-0.03 \\
(0.04)\end{array}$ \\
\hline
\end{tabular}

Notes. standard errors in parentheses. ${ }^{*} p<0.1,{ }^{* *} p<0.05,{ }^{* *} p<0.01$.

Source: MHLS 2010 and 2012. 
Afraid of going to nearest town out of fear of being mugged, attacked or abducted

0.11

(0.10)

Afraid of going within current area out of fear of being mugged, attacked or abducted

$-0.032$

$(0.11)$

Poor/unreliable amenities provision in neighbourhood

$-0.10$

(0.18)

No police station in area

0.14

$(0.27)$

Respondent would like to move out of area

$-0.34^{* * *}$

(0.13)

Feel female members are safe at day

0.10

(0.20)

Feel female members are safe at day

0.062

(0.11)

Constant

$4.33^{* * *}$

(1.57)

Respondent and Household controls

Yes

Neighbourhood controls

Yes

Yes

Lagged neighbourhood means of covariates

Observations

1071

Degrees of freedom

25.000

Chi-squared

215.919

Prob $>$ chi2

0.000

Notes: standard errors in parentheses. ${ }^{*} p<0.1,{ }^{* *} p<0.05,{ }^{* * *} p<0.01$

Source: authors' calculations based on MHLS 2010 and 2012.

Table A7: Heckman second stage: effect of riot on social capital

\begin{tabular}{lccc}
\hline & $\begin{array}{c}(1) \\
\text { Organization }\end{array}$ & $\begin{array}{c}(2) \\
\text { Trust }\end{array}$ & $\begin{array}{c}(3) \\
\text { Discussions }\end{array}$ \\
\hline At least 30\% of neighbourhood witnessed a riot $(\mathrm{d})$ & $0.48^{* * *}$ & -0.087 & $-0.16^{*}$ \\
& $(0.18)$ & $(0.25)$ & $(0.089)$ \\
Inverse Mills Ratio & -0.11 & 0.56 & $-0.70^{*}$ \\
& $(0.64)$ & $(0.46)$ & $(0.36)$ \\
Respondent and Household controls & Yes & Yes & Yes \\
Neighbourhood controls and means & & & \\
\hline Observations & Yes & Yes & Yes \\
Degrees of freedom & 853 & 853 & 853 \\
Chi-squared & 21.000 & 21.000 & 21.000 \\
Prob > chi2 & 92.547 & 75.773 & 105.186 \\
Number of clusters & 0.000 & 0.000 & 0.000 \\
\hline
\end{tabular}

Notes: marginal effects; standard errors in parentheses. (d) for discrete change of dummy variable from 0 to $1 .{ }^{*} p<0.1,{ }^{* *} p<0.05,{ }^{* * *} p<0.01$

Source: authors' calculations based on MHLS 2010 and 2012. 
Table A8: Effect of riot interacted with social diversity on social capital

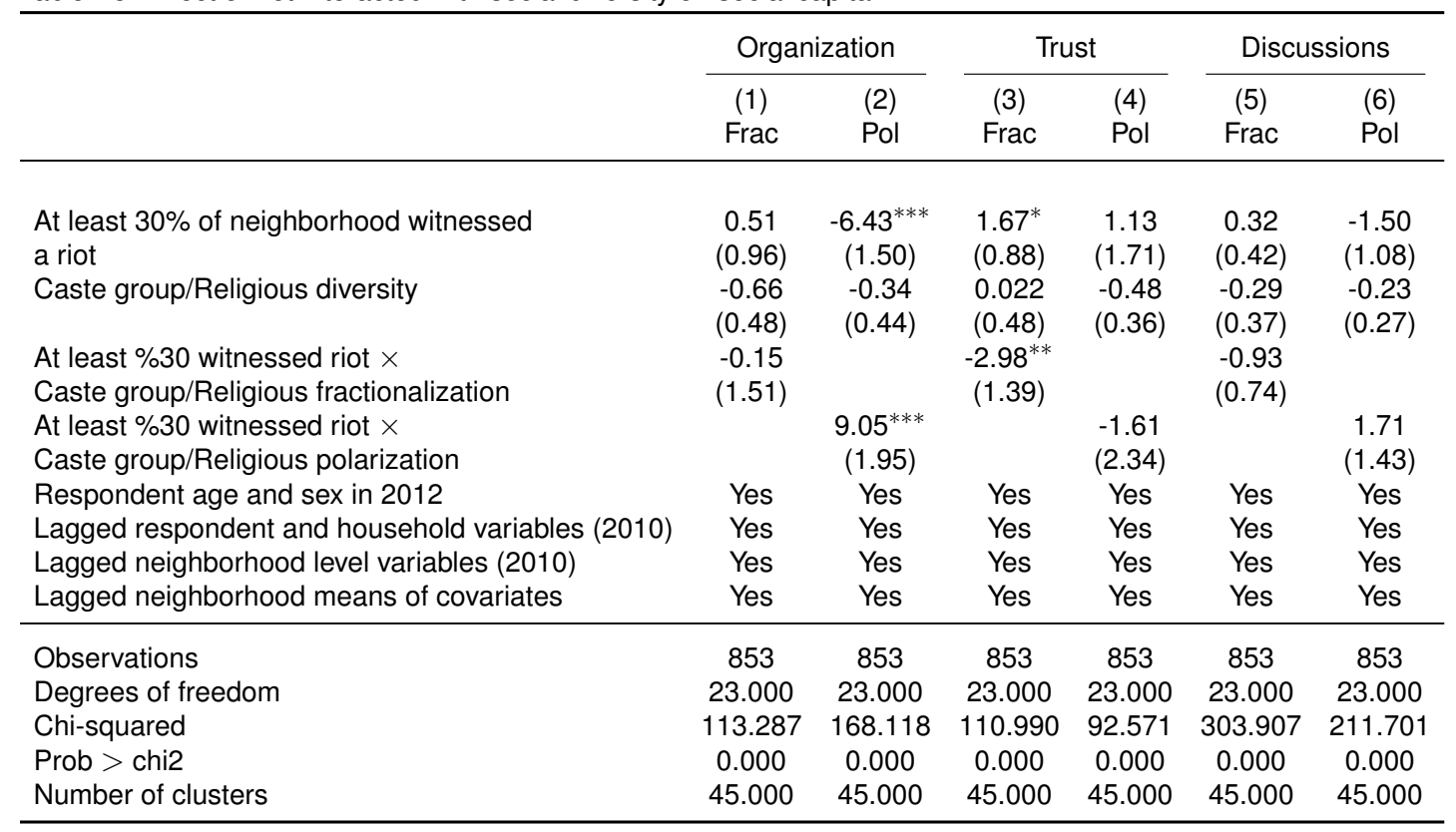

Notes: standard errors in parentheses. ${ }^{*} p<0.1,{ }^{* *} p<0.05,{ }^{* * *} p<0.01$

Source: authors' calculations based on MHLS 2010 and 2012. 
Table A9: Test of orthogonality of vignette character assignment

\begin{tabular}{|c|c|c|c|c|}
\hline & \multicolumn{3}{|c|}{ Mean } & \multirow{2}{*}{$\begin{array}{c}\begin{array}{c}\text { Joint significance of } \\
\text { Deshpande and Hanit }\end{array} \\
\text { Orthogonality test }\end{array}$} \\
\hline Characteristic & Deshpande & Hanif & Yadev & \\
\hline \multicolumn{5}{|l|}{ Main variables in analysis } \\
\hline At least $30 \%$ of neighbourhood witnessed a riot & 0.17 & 0.24 & 0.23 & - \\
\hline Caste group/religious fractionalization & 0.54 & 0.52 & 0.54 & - \\
\hline Caste group/religious polarization & 0.69 & 0.68 & 0.69 & - \\
\hline Average household migrated in neighbourhood & 0.07 & 0.07 & 0.08 & - \\
\hline \multicolumn{5}{|l|}{ Respondent level variables 2012} \\
\hline Age (2012) & 39.05 & 39.33 & 38.27 & 0.525 \\
\hline Sex $(2012)$ & 0.38 & 0.31 & 0.35 & 0.277 \\
\hline \multicolumn{5}{|l|}{ Lagged respondent and household variables } \\
\hline Age (2010) & 33.68 & 34.89 & 33.75 & 0.277 \\
\hline $\operatorname{Sex}(2010)$ & 0.37 & 0.31 & 0.36 & 0.384 \\
\hline Dwelling made of permanent material & 0.51 & 0.55 & 0.51 & 0.502 \\
\hline Household is Muslim & 0.39 & 0.39 & 0.39 & 0.851 \\
\hline Household size & 6.5 & 6.9 & 6.3 & 0.14 \\
\hline Household rents $(0=$ own $)$ & 0.12 & 0.13 & 0.15 & 0.547 \\
\hline Log per capita monthly income & 6.82 & 6.82 & 6.88 & 0.804 \\
\hline Marathi mother tongue & 0.49 & 0.51 & 0.52 & 0.909 \\
\hline Length of time in neighbourhood & 18.5 & 19.65 & 18.78 & 0.426 \\
\hline Unsafe location nearby & 0.11 & 0.08 & 0.1 & 0.322 \\
\hline Household belongs to major social group & 0.59 & 0.68 & 0.6 & $0.093^{*}$ \\
\hline \multicolumn{5}{|l|}{ Neighbourhood variables } \\
\hline Police station in neighbourhood & 0.1 & 0.14 & 0.12 & - \\
\hline Chowk in neighbourhood & 0.43 & 0.48 & 0.42 & - \\
\hline Hindu temple in neighbourhood & 0.51 & 0.56 & 0.51 & - \\
\hline Mosque in neighbourhood & 0.39 & 0.48 & 0.38 & - \\
\hline Market in neighbourhood & 0.21 & 0.21 & 0.23 & - \\
\hline $\begin{array}{l}\text { Orthogonality test: Joint significance } \\
\text { of covariates on each character assignment }\end{array}$ & 0.516 & 0.855 & 0.119 & \\
\hline
\end{tabular}

Note: ${ }^{*} p<0.1,{ }^{* *} p<0.05,{ }^{* * *} p<0.01$.

Source: authors' calculations using MHLS 2010 and 2012. 